\title{
Immune activation caused by vascular oxidation promotes fibrosis and hypertension
}

\author{
Jing Wu, ${ }^{1}$ Mohamed A. Saleh, ${ }^{1,2}$ Annet Kirabo, ${ }^{1}$ Hana A. Itani, ${ }^{1}$ Kim Ramil C. Montaniel, ${ }^{1}$ Liang Xiao, ${ }^{1}$ Wei Chen, ${ }^{1}$ \\ Raymond L. Mernaugh, ${ }^{3}$ Hua Cai, ${ }^{4}$ Kenneth E. Bernstein, ${ }^{5}$ Jörg J. Goronzy, ${ }^{6}$ Cornelia M. Weyand, ${ }^{6}$ John A. Curci, ${ }^{7}$ \\ Natalia R. Barbaro, ${ }^{8}$ Heitor Moreno, ${ }^{8}$ Sean S. Davies, ${ }^{1}$ L. Jackson Roberts II, ${ }^{1}$ Meena S. Madhur, ${ }^{1}$ and David G. Harrison ${ }^{1}$ \\ 'Division of Clinical Pharmacology, Department of Medicine, Vanderbilt University Medical Center, Nashville, Tennessee, USA. ²Department of Pharmacology and Toxicology, Faculty of Pharmacy, \\ Mansoura University, Mansoura, Egypt. ' Department of Biochemistry, School of Medicine, Vanderbilt University, Nashville, Tennessee, USA. 'Division of Molecular Medicine and Cardiology, \\ Cardiovascular Research Laboratories, Departments of Anesthesiology and Medicine, David Geffen School of Medicine at UCLA, Los Angeles, California, USA. ${ }^{5}$ Department of Biomedical Sciences and \\ Department of Pathology and Laboratory Medicine, Cedars-Sinai Medical Center, Los Angeles, California, USA. 'Division of Immunology and Rheumatology, Department of Medicine, \\ Stanford University, Stanford, California, USA. 'Division of Vascular Surgery, Department of Surgery, Vanderbilt University Medical Center, Nashville, Tennessee, USA. \\ ${ }^{8}$ Department of Pharmacology, Faculty of Medical Sciences, Cardiovascular Pharmacology Laboratory, University of Campinas, Campinas, Brazil.
}

\begin{abstract}
Vascular oxidative injury accompanies many common conditions associated with hypertension. In the present study, we employed mouse models with excessive vascular production of ROS ( $\mathrm{tg}^{\mathrm{sm} / \mathrm{p}^{22 p h o x}}$ mice, which overexpress the NADPH oxidase subunit p22 $2^{\text {phox }}$ in smooth muscle, and mice with vascular-specific deletion of extracellular SOD) and have shown that these animals develop vascular collagen deposition, aortic stiffening, renal dysfunction, and hypertension with age. T cells from $\operatorname{tg}^{\text {sm/p22phox }}$ mice produced high levels of IL-17A and IFN- $\gamma$. Crossing $\operatorname{tg}^{\text {sm/p22phox }}$ mice with lymphocyte-deficient Rag ${ }^{1^{/-}}$mice eliminated vascular inflammation, aortic stiffening, renal dysfunction, and hypertension; however, adoptive transfer of T cells restored these processes. Isoketal-protein adducts, which are immunogenic, were increased in aortas, DCs, and macrophages of $\mathrm{tg}^{\mathrm{sm} / \mathrm{p} 22 \text { phox }}$ mice. Autologous pulsing with $\mathrm{tg}^{\mathrm{sm} / \mathrm{p22phox}}$ aortic homogenates promoted DCs of $\mathrm{tg}^{\mathrm{sm} / \mathrm{p}^{22 p h o x}}$ mice to stimulate T cell proliferation and production of IFN- $\gamma$, IL-17A, and TNF- $\alpha$. Treatment with the superoxide scavenger tempol or the isoketal scavenger 2-hydroxybenzylamine (2-HOBA) normalized blood pressure; prevented vascular inflammation, aortic stiffening, and hypertension; and prevented DC and T cell activation. Moreover, in human aortas, the aortic content of isoketal adducts correlated with fibrosis and inflammation severity. Together, these results define a pathway linking vascular oxidant stress to immune activation and aortic stiffening and provide insight into the systemic inflammation encountered in common vascular diseases.
\end{abstract}

\section{Introduction}

The normal aorta expands to accommodate a portion of the ejected blood during cardiac contraction and then recoils during cardiac relaxation. This capacitance, or Windkessel function, of the aorta reduces systolic pressure and maintains pressure and peripheral perfusion during diastole. In several conditions - including aging, autoimmune diseases, cigarette smoking, diabetes, obesity, and hypertension - the aorta stiffens, leading to loss of the Windkessel function and systolic hypertension. Pulse wave velocity (PWV), a surrogate measure of aortic stiffness, predicts untoward outcomes in aged and hypertensive humans $(1,2)$. A recent analysis of the Framingham population indicates that aortic stiffening precedes hypertension and that higher forward pressure wave amplitude, a hallmark of aortic stiffening, is associated with increased risk for incident cardiovascular diseases $(3,4)$.

A common feature of many conditions associated with aortic stiffening is vascular oxidant stress. Clinically, plasma levels of myeloperoxidase and $\mathrm{F}_{2}$-isoprostanes correlate with arterial stiff-

Conflict of interest: The authors have declared that no conflict of interest exists. Submitted: January 2, 2015; Accepted: October 9, 2015.

Reference information: / Clin Invest. 2016;126(1):50-67. doi:10.1172/JCI80761. ening in humans (5). Studies in experimental animals have implicated ROS in fibrotic changes in blood vessels, lungs, skin, and other tissues $(6,7)$. In addition to oxidative events, chronic inflammation is associated with arterial stiffness in humans (8-10). Patients with systemic lupus erythematosus, rheumatoid arthritis, and psoriasis exhibit increased aortic stiffness, and TNF- $\alpha$ antagonists improve parameters of aortic stiffness in patients with rheumatoid arthritis $(11,12)$. We have shown that hypertension is associated with the infiltration of immune cells into the adventitia and periadventitial fat, as well as the activation of $\mathrm{T}$ cells that release proinflammatory cytokines such as IL-17A, IFN- $\gamma$, and TNF- $\alpha$ (13, 14). IL-17A induces collagen synthesis in fibroblasts via activation of p38 MAP kinase (15). IFN- $\gamma$ also promotes hypertension-related fibrosis in the heart, arteries, and the kidney (16).

A potential mechanism linking oxidative injury to immune activation and inflammation relates to modification of self-proteins. In particular, isoketals - alternatively referred to as isolevuglandins or $\gamma$-ketoaldehydes - are formed from fatty acid oxidation and react with protein lysines to form oxidized pyrrole adducts. These modified proteins become auto-antigens and can elicit antibody formation (17). We have recently shown that hypertension is associated with accumulation of isoketal-adducted 
A

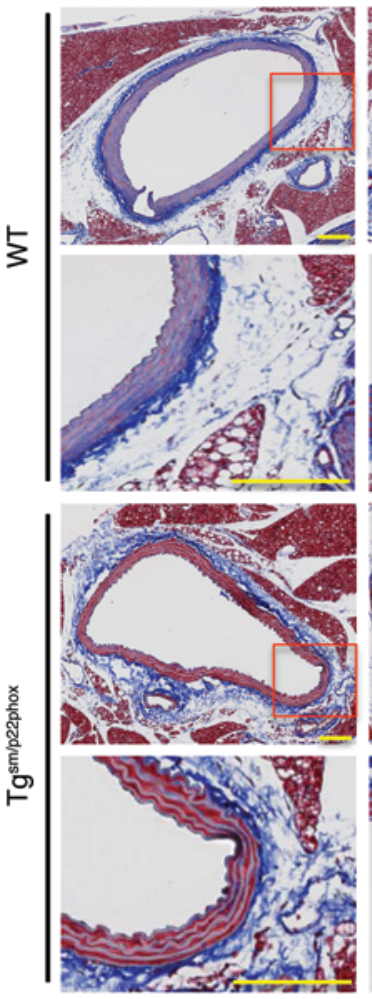

E

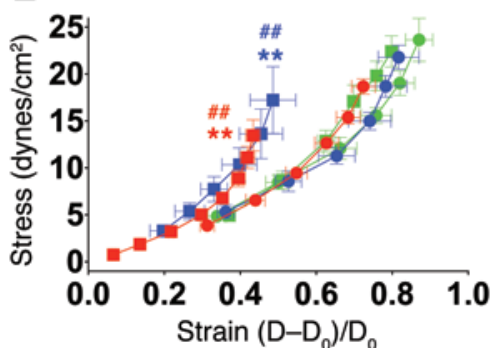

$6 \mathrm{mo}$

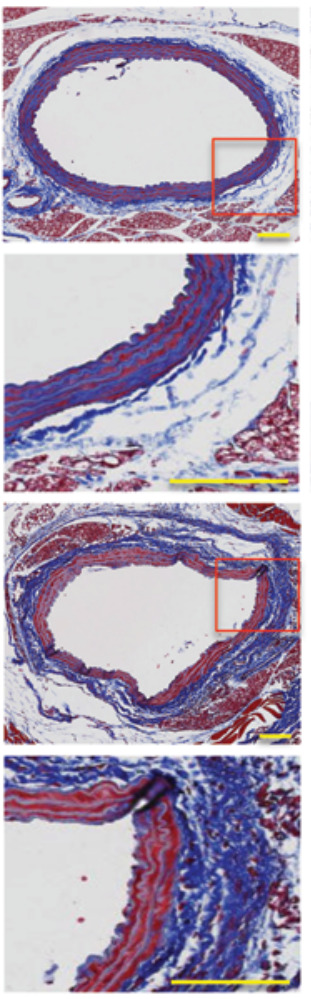

\begin{abstract}
$\mathbf{F}$
\end{abstract}

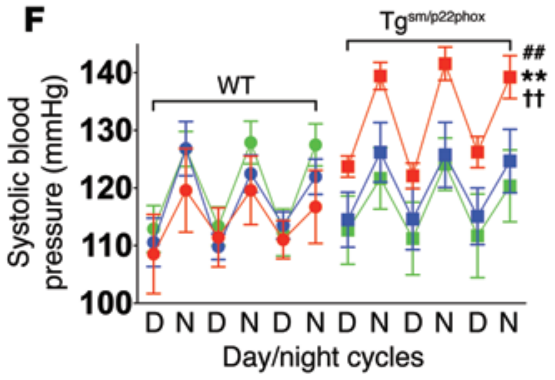

C
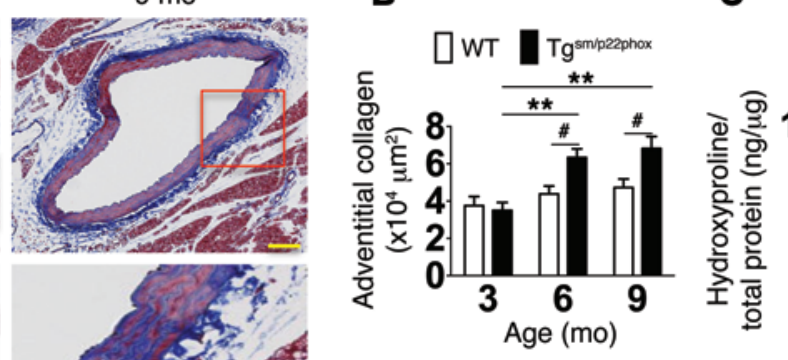

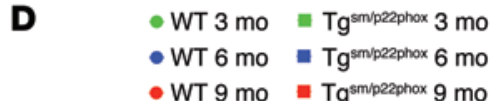

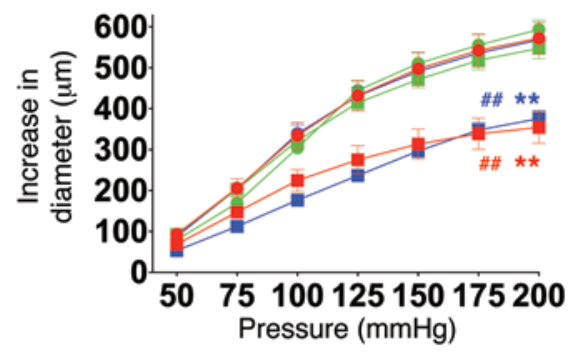

Figure 1. Tg $^{\text {sm/p22phox }}$ mice develop age-related aortic stiffening and hypertension. (A) Effects of aging on vascular collagen deposition in WT and tg ${ }^{\text {sm/p22phox }}$ mice. Perfusion-fixed sections of the thoracic aortas were sectioned $(6 \mu \mathrm{m})$ and stained with Masson's trichome to highlight collagen (blue). Areas within the red boxes were magnified $(\times 20)$ and shown below the original images $(\times 6)$. Scale bars: $100 \mu \mathrm{m}$. (B) Adventitial collagen area was quantified by planimetry. ${ }^{\# P}<0.05$ vs. WT; ${ }^{* *} P<0.01$ vs. 3 months. (C) Aortic collagen quantification by hydroxyproline assay. (D and $\left.\mathbf{E}\right)$ Freshly isolated aortas were mounted on a myograph system in $\mathrm{Ca}^{2+}$-free buffer to determine pressure-diameter relationships. Stress-strain relationships were constructed from intraluminal pressure, wall thickness, and inner and outer diameters. These parameters were measured at $25 \mathrm{mmHg}$ step changes in pressure from 0-200 mmHg. ${ }^{* *} P<0.01$ vs. Tg 3 months; ${ }^{\# \#} P<0.01$ vs. WT. (F and $\mathbf{G}$ ) Telemetry blood pressure of WT and tg ${ }^{\text {sm/p22phox }}$ mice at 3,6 , and 9 months of age. ${ }^{\dagger} P<0.05$ vs. Tg 6 months; ${ }^{\text {tt}} P<0.01$ vs. Tg 6 months. Data were analyzed using 2-way ANOVA; $n=6-9$.

proteins within DCs. These adducts markedly enhance DC surface expression of the costimulatory molecules CD80 and CD86, as well as cytokine production (18). Moreover, DCs modified in this fashion robustly drive $\mathrm{T}$ cell activation and can prime hypertension when adoptively transferred to naive mice. The mechanisms leading to DC acquisition of isoketal-adducted proteins remain undefined. In particular, it is unknown if DCs can acquire oxidatively modified proteins produced by other cells; however, such a process could link oxidative injury in other cells to immune activation and might explain how oxidative stress leads to vascular inflammation and, ultimately, aortic stiffening.

In the present studies, we employed mice with chronic vascular oxidative stress to define a pathway that links oxidative damage to immune activation via formation of immunoreactive isoketal-pro- tein adducts, vascular inflammation, aortic stiffening, renal dysfunction, and hypertension. These experiments provide new insight into how diverse conditions diminish aortic compliance, alter renal function, and ultimately cause hypertension. These findings also show how vascular diseases associated with vascular oxidative injury can lead to systemic immune activation and inflammation.

\section{Results}

Chronic vascular oxidative stress induces aortic stiffening and hypertension. As an initial approach to determine if vascular oxidative stress promotes aortic stiffening, we studied $\operatorname{tg}^{s \mathrm{sm} / \mathrm{p2} 2 \mathrm{phox}}$ mice. These animals have smooth muscle-targeted overexpression of p22 $2^{\text {phox }}$, a docking subunit of all murine NADPH oxidase catalytic subunits (19). Vessels from these mice exhibit increased vascular 

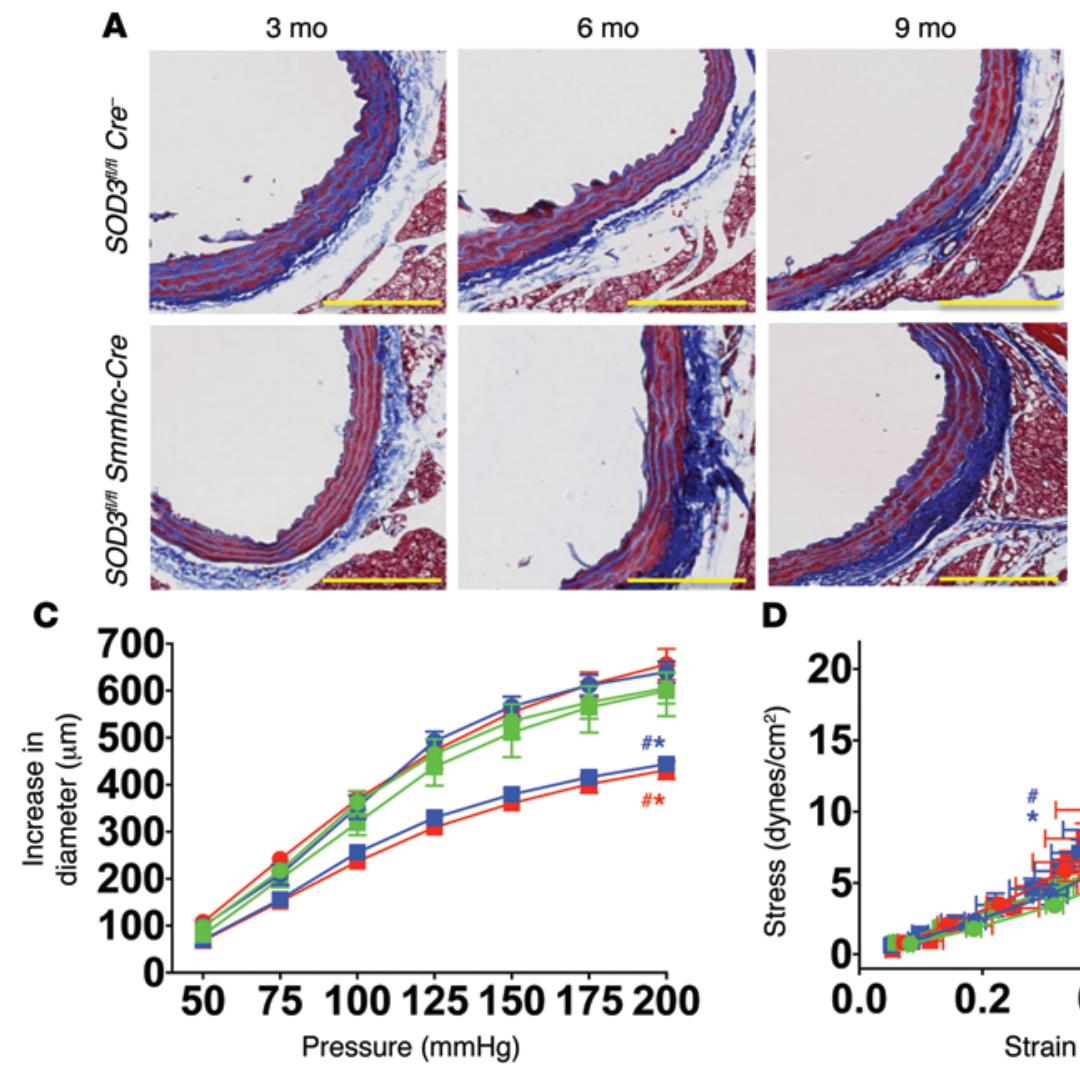

B
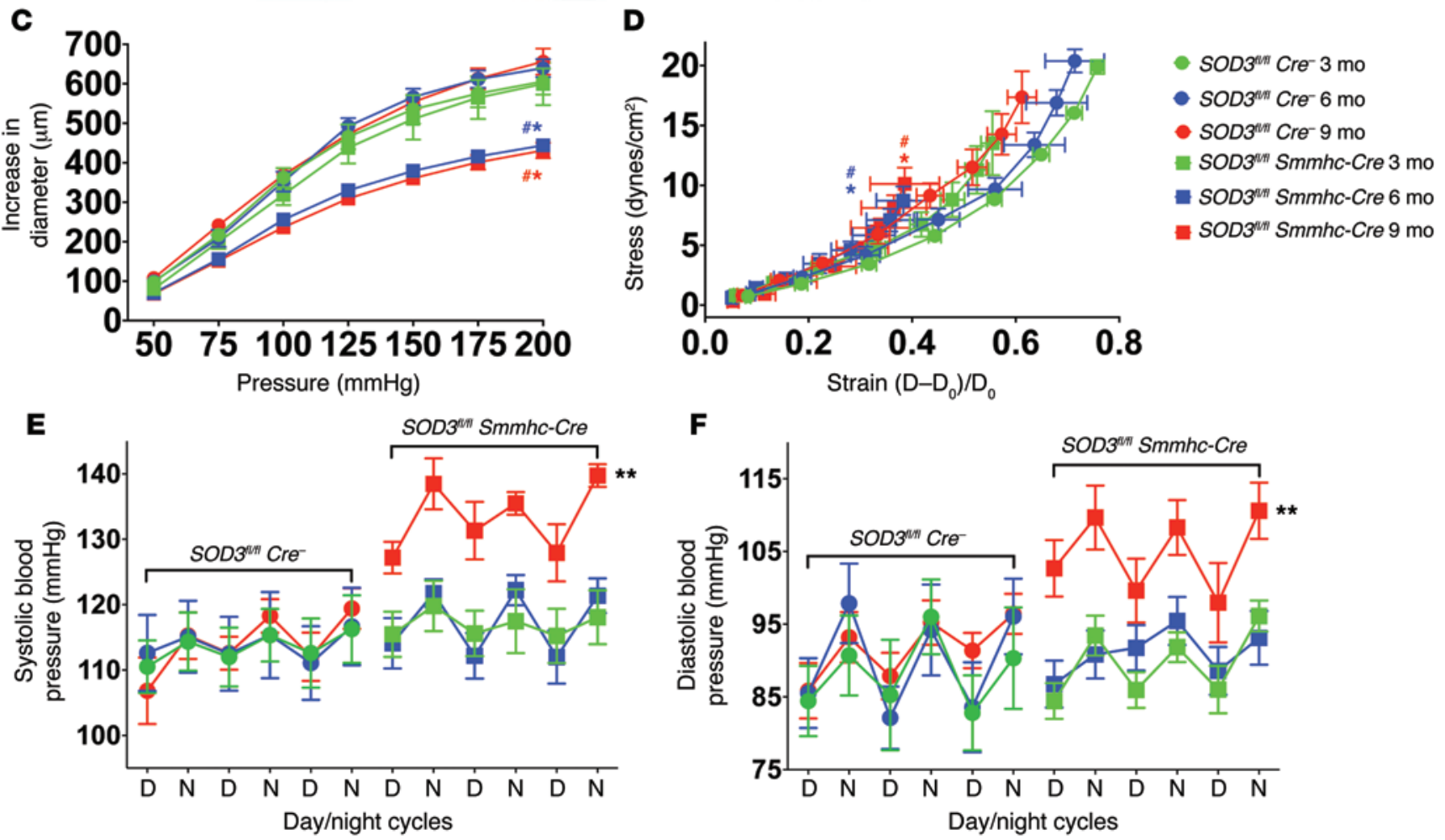

Figure 2. Vascular oxidative stress induced by deletion of smooth muscle Sod3 promotes age-related aortic stiffening and hypertension. (A) Masson's

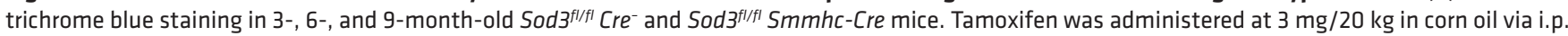
injection at 10 weeks of age. Images are $\times 20$ magnification. Scale bars: $100 \mu \mathrm{m}$. (B) Aortic hydroxyproline content. (C and D) Pressure diameter relationship and stress-strain relationships. (E and F) Blood pressure measured by radiotelemetry $(n=6-8) . \# P<0.05$ vs. Cre ${ }^{-1-} ;{ }^{*} P<0.05$ vs. Sod $3^{f l / f l}$ Smmhc Cre 3 month; ${ }^{* *} P<0.05$ vs. Sod3 $3^{f / f l}$ Smmhc-Cre 3 month. Aortic hydroxyproline content was analyzed using 2-way ANOVA. Pressure diameter relationships, stress-strain relationships, and blood pressures were analyzed using 1-way ANOVA with repeated measures.

Nox1 expression and a 2-fold increase in vascular superoxide and hydrogen peroxide production (19). Masson's trichrome staining revealed minimal collagen staining in the aorta of WT mice at either 3, 6, or 9 months of age (Figure 1, A and B). In contrast, aortic adventitial collagen content was increased in the $\mathrm{tg}^{\mathrm{sm} / \mathrm{p} 22 \mathrm{phox}}$ mice at 6 and 9 months of age. Hydroxyproline analysis confirmed that aortic collagen content was increased by about 2 -fold at 6 and 9 months of age in $\mathrm{tg}^{\mathrm{sm} / \mathrm{p} 22 \mathrm{phox}}$ mice (Figure 1C).

Mechanical properties of the aortas of WT and $\operatorname{tg}^{\text {sm/p22phox }}$ mice were studied ex vivo in a pressurized vessel apparatus. Aortas from WT mice at 3, 6, and 9 months of age demonstrated identical increases in diameter as intraluminal pressure was increased (Fig-

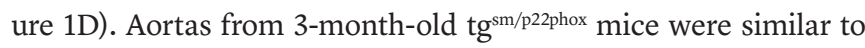
those of WT mice, but at 6 and 9 months of age, aortas from these mice demonstrated depressed pressure-diameter relationships. This was reflected by a leftward shift in the stress-strain curves (Figure 1E), indicating increased stiffness of the aortas of $\mathrm{tg}^{\mathrm{sm} / \mathrm{p} 22 \mathrm{phox}}$ mice at 6 and 9 months of age.

To confirm aortic stiffening in vivo, we measured PWV as previously described (20). At 3 months of age, PWV in WT and $\mathrm{tg}^{\text {sm/p22phox }}$ mice was similar; however, with aging, this parameter increased in $\operatorname{tg}^{\text {sm/p22phox }}$ mice but did not significantly change in WT mice (Supplemental Figure 1; supplemental material available online with this article; doi:10.1172/JCI80761DS1). 
A

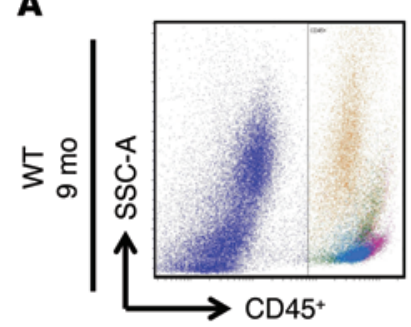

E

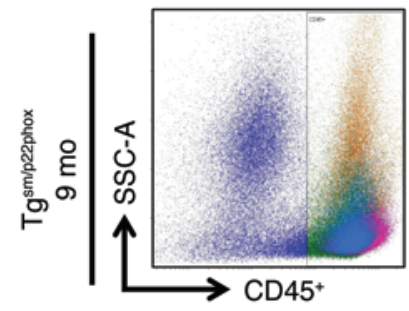

I

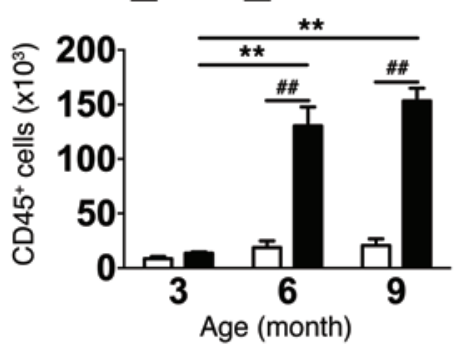

B

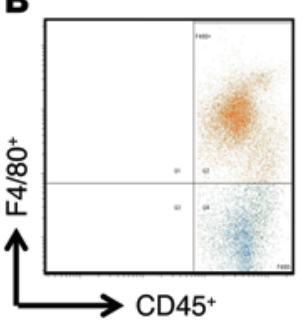

$\mathbf{F}$

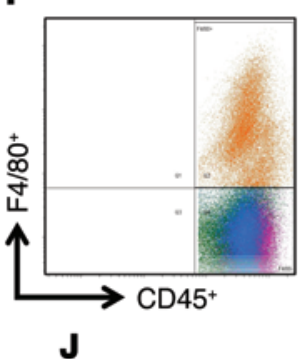

C

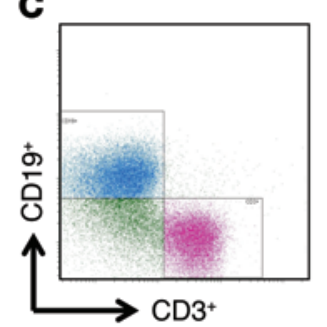

G

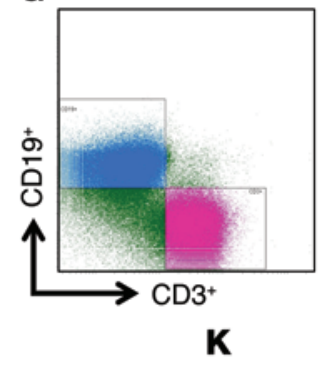

D

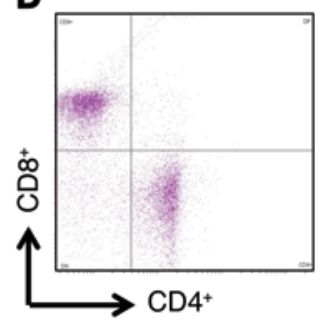

H
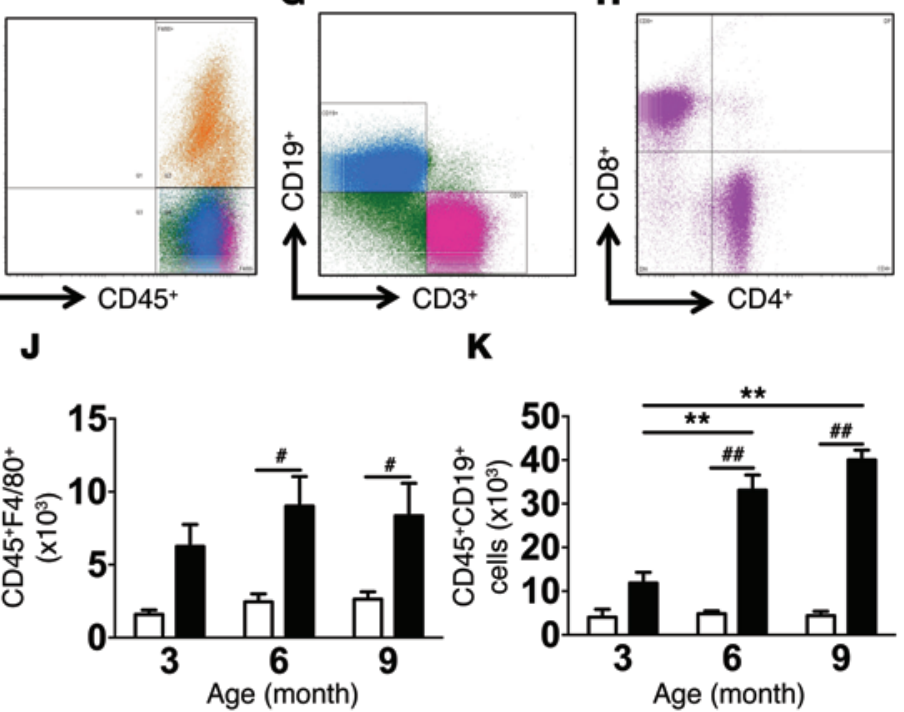

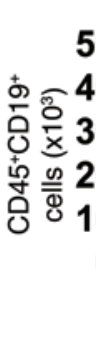

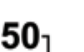

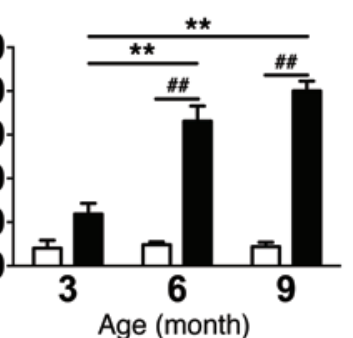

M
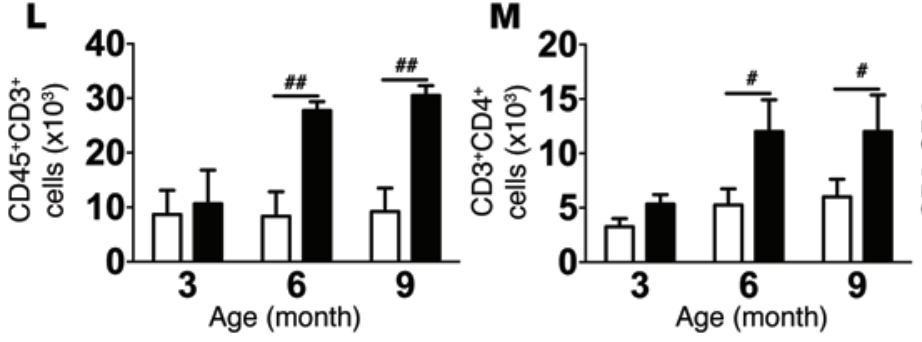

N

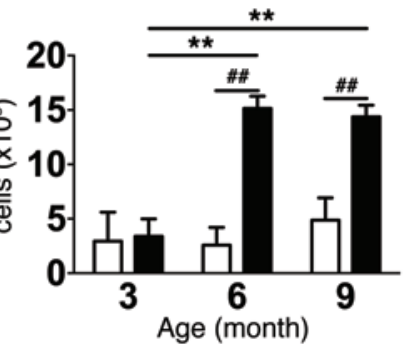

Figure 3. Flow cytometry analysis of inflammatory cells in the aorta of WT and tg $^{\text {sm/p22phox mice. Single cell }}$ suspensions were prepared from freshly isolated mouse aortas via enzymatic digestion and mechanical dissociation. Live cell singlets were analyzed for vascular inflammatory cells. (A-H) $\mathrm{CD} 45^{+}$total leukocytes, $\mathrm{F} 4 / 80^{+}$macrophages, CD19+ B lymphocytes, $\mathrm{CD}^{+} \mathrm{T}$ lymphocytes, and $\mathrm{CD}^{+} / \mathrm{CD}^{+} \mathrm{T}$ cell subsets were identified in the aorta of 9-month-old WT (A-D) and

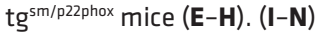
Quantification of infiltrating leukocyte subsets using 2-way ANOVA $(n=6-8) .{ }^{* *} P<0.01$ Vs. $\mathrm{Tg}^{\text {sm/p22phox; }}{ }^{*} P<0.05$; $\# \#<0.01$.
Although aortic stiffening developed at 6 months of age in $\operatorname{tg}^{\text {sm/p22phox }}$ mice, their blood pressure remained normal at this time. At 9 months of age, however, $\operatorname{tg}^{\text {sm/p22phox }}$ mice developed moderate hypertension, while WT mice remained normotensive (Figure 1, F and G). Analysis of heart rate variability showed an increase in the low-frequency to high-frequency ratio (LF/HF) in both WT and $\operatorname{tg}^{\mathrm{sm} / \mathrm{p} 22 \text { phox }}$ mice at 6 and 9 months of age, but this was not different between the genotypes (Supplemental Figure 2). Thus, in $\operatorname{tg}^{\text {sm/p22phox }}$ mice, aortic stiffening precedes blood pressure elevation, mimicking the sequence of these events in humans. This increase in blood pressure does not seem to be related to increased sympathetic outflow.

The effects of oxidative stress on aortic stiffening and agerelated hypertension were confirmed in mice with vascular smooth

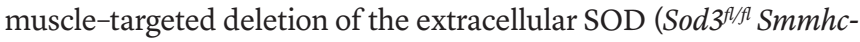
Cre mice, another model of vascular oxidative stress (21). Deletion of Sod3 was induced at 10 weeks of age by injection of tamoxifen. As controls, Sod $3^{f / f l}$ mice lacking Cre recombinase were also treated with tamoxifen. At 3 months of age, shortly after Sod3 deletion, there was no significant difference in aortic collagen between these 2 groups of animals, as estimated by Masson's trichrome staining or quantified by hydroxyproline content (Figure 2, A and B). By 6 months of age, mice with Sod3 deletion had a marked increase in adventitial collagen compared with $\operatorname{Sod} 3^{f / f l}$ mice lacking Cre recombinase. This was associated with development of aortic stiffening (Figure 2, C and D) but no increase in blood pressure (Figure 2, E and F). By 9 months of age, the SOD3-deficient mice exhibited not only aortic stiffening, but also a significant elevation of blood pressure (Figure 2, A-F). Collectively, these data recapitulate our finding in $\mathrm{tg}^{\mathrm{sm} / \mathrm{p} 22 p h o x}$ mice and support a role of vascular ROS in promoting vascular fibrosis, aortic stiffening, and age-related hypertension.

Oxidative stress-induced vascular inflammation contributes to age-related hypertension. We and others have previously demonstrated that vascular inflammation contributes to the development of hypertension and aortic stiffening $(13-16,22)$. We therefore sought to determine if chronic oxidative stress promotes vascular inflammation in $\mathrm{tg}^{\mathrm{sm} / \mathrm{p} 22 \mathrm{phox}}$ mice. Flow cytometry of single cell suspensions revealed that total leukocytes, monocyte/macrophages, B cells, total $\mathrm{T}$ cells, and $\mathrm{CD} 4^{+}$and $\mathrm{CD} 8^{+} \mathrm{T}$ cell subsets were all increased in aortas of 6- and 9-month-old $\mathrm{tg}^{\mathrm{sm} / \mathrm{p} 22 \text { phox }}$ mice compared with similarly aged WT mice (Figure 3, A-N). IHC using anti-CD3 indicated that $\mathrm{T}$ lymphocytes were predominantly 
A
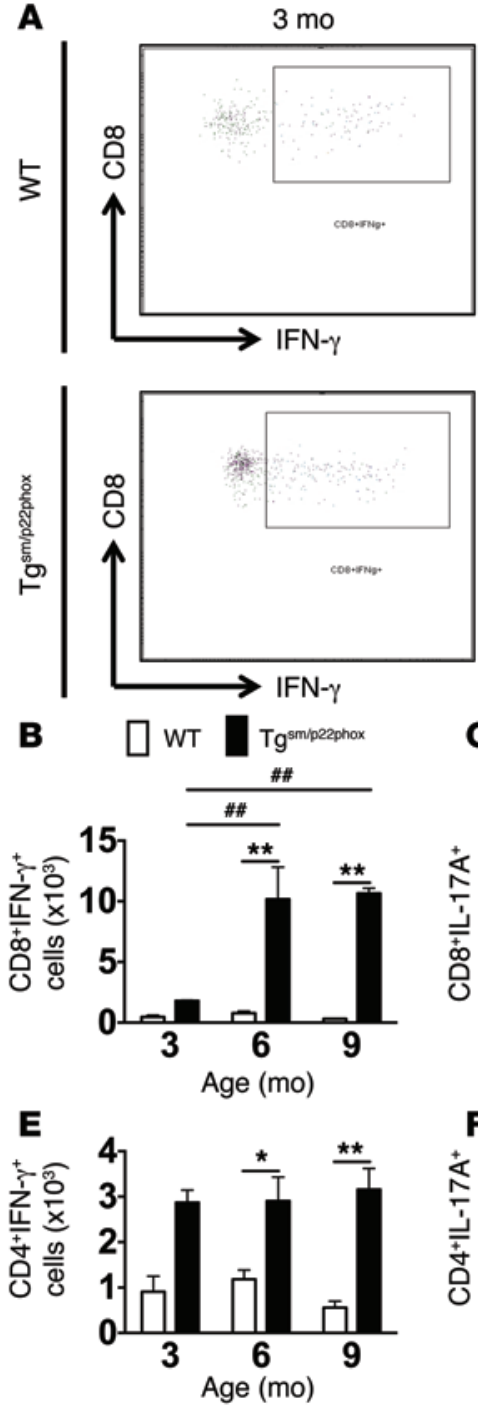
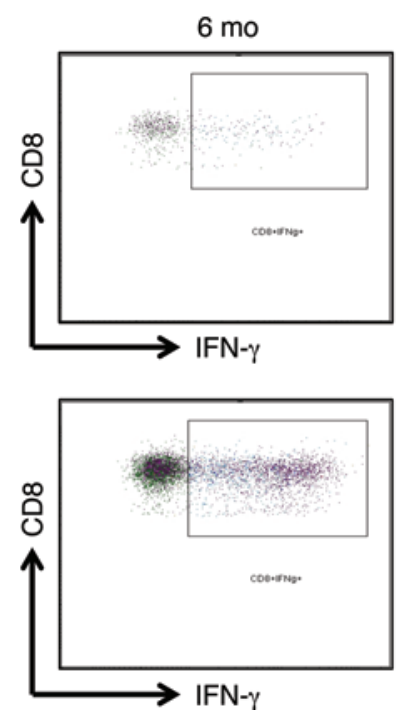

C
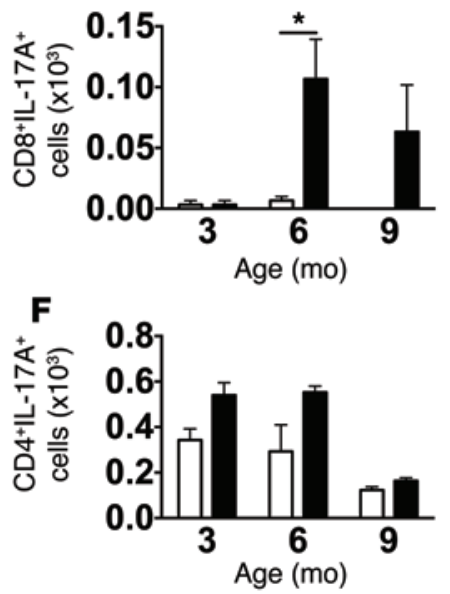
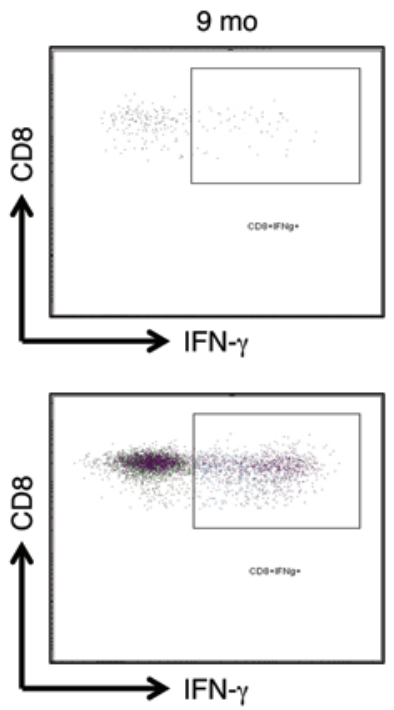

D
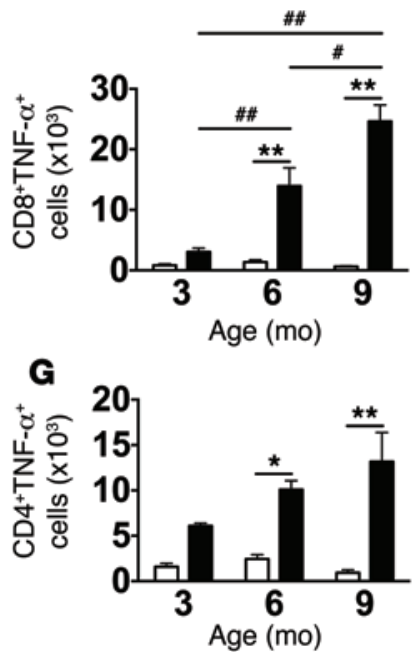

Figure 4. Production of cytokines by aortic $T$ cells using intracellular staining. One million splenocytes were stimulated with ionomycin and phorbol myristate acetate and brefeldin $\mathrm{A}$ at $37^{\circ} \mathrm{C}$ for 5 hours. Intracellular staining was then performed with the Cytofix/Cytoperm Plus fixation and permeabilization solution kit using anti-IL-17A and anti-IFN- $\gamma$ antibodies. (A) Representative images of IFN- $\gamma$ producing CD8 ${ }^{+} T$ cells of WT and $\mathrm{tg}^{\mathrm{sm} / \mathrm{p} 22 \text { phox }}$ mice at 3,6 , and 9 months of age. (B-D) Quantification of $\mathrm{CD} 8^{+} T$ cells producing IFN- $\gamma$, IL-17A, and TNF- $\alpha$. (E-G) Quantification of CD4 ${ }^{+} T$ cells producing IFN- $\gamma$, IL-17A, and TNF- $\alpha .{ }^{*} P<0.01$ vs. WT; ${ }^{* *} P<0.01$ vs. WT; ${ }^{\#} P<0.05$ vs. 6 months; $\# P<0.01$ vs. 3 months. These data were analyzed using 2-way ANOVA. located in the adventitia and perivascular fat of thoracic aortas in $\mathrm{Tg}^{\mathrm{sm} / \mathrm{p} 22 \text { phox }}$ mice at 6 and 9 months of age, compared with agematched WT mice (Supplemental Figure 3).

In additional experiments, we examined the production of cytokines by aortic $\mathrm{T}$ cells using intracellular staining. At 3 months of age, the few $\mathrm{T}$ cells in the aorta of $\mathrm{tg}^{\mathrm{sm} / \mathrm{p} 22 \text { phox }}$ mice produced minimal amounts of IFN- $\gamma$, IL-17A, or TNF- $\alpha$; however, by 6 and 9 months, the number of both $\mathrm{CD}^{+}$and $\mathrm{CD}^{+} \mathrm{T}$ cells in the aorta producing these cytokines was significantly increased (Figure 4, A-G).

Chronic vascular oxidative stress promotes age-related renal inflammation, fibrosis, and dysfunction. We considered the hypothesis that chronic vascular oxidative stress might predispose to renal inflammation and dysfunction. Flow cytometry of kidney single cell suspensions showed a significant increase in total leukocytes, monocyte/ macrophages, DCs, total T cells, and both $\mathrm{CD} 4^{+}$and $\mathrm{CD} 8^{+} \mathrm{T}$ cells at 9 months of age but not at earlier time points in $\mathrm{tg}^{\mathrm{sm} / \mathrm{p2} 2 \mathrm{phox}}$ mice (Figure $5, A-G$ ). IHC showed that $\mathrm{CD}^{+}$cells accumulate in the periglomerular and perivascular regions of 9-month-old $\operatorname{tg}^{\text {sm/p22phox }}$ mice. In contrast, there was minimal accumulation of immune cells, as assessed by either flow cytometry or IHC in aged WT mice (Figure 6A). In parallel with T cell infiltration, Masson's trichrome staining revealed perivascular collagen deposition in the kidney of 9-monthold $\mathrm{tg}^{\mathrm{sm} / \mathrm{p} 22 \mathrm{phox}}$ mice but not WT mice (Figure 6B). These changes in renal inflammation and fibrosis were paralleled by a decline in the capacity of mice to excrete a volume and sodium challenge. Mice received an i.p. injection of normal saline equal to $10 \%$ of their body weight, and the urine volume and sodium excreted in the subsequent 4 hours was monitored as previously described $(23,24)$. This analysis revealed that $\mathrm{tg}^{\mathrm{sm} / \mathrm{p} 22 \text { phox }}$ mice exhibited an accelerated decline in their ability to excrete this volume and sodium load with aging (Figure 6, C and D). Thus, chronic vascular oxidative stress initially causes vascular inflammation and subsequent renal inflammation, fibrosis, and dysfunction. These perturbations of renal function temporally correspond to the elevation of blood pressure observed in these mice.

$T$ lymphocytes are required for collagen deposition, aortic stiffening, and hypertension in mice with chronic vascular oxidative stress. Because $\mathrm{T}$ cells contribute to hypertension in other models, we crossed $\mathrm{tg}^{\mathrm{sm} / \mathrm{p} 22 \text { phox }}$ mice with mice lacking the $\mathrm{Rag}-\mathrm{1}^{-/-}$mice, to gen-

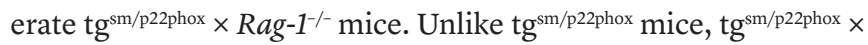
Rag-1 $1^{-/-}$mice did not develop collagen deposition (Figure 7, A-C), aortic stiffening (Figure 7, D and E), or hypertension (Figure 7, F 
A
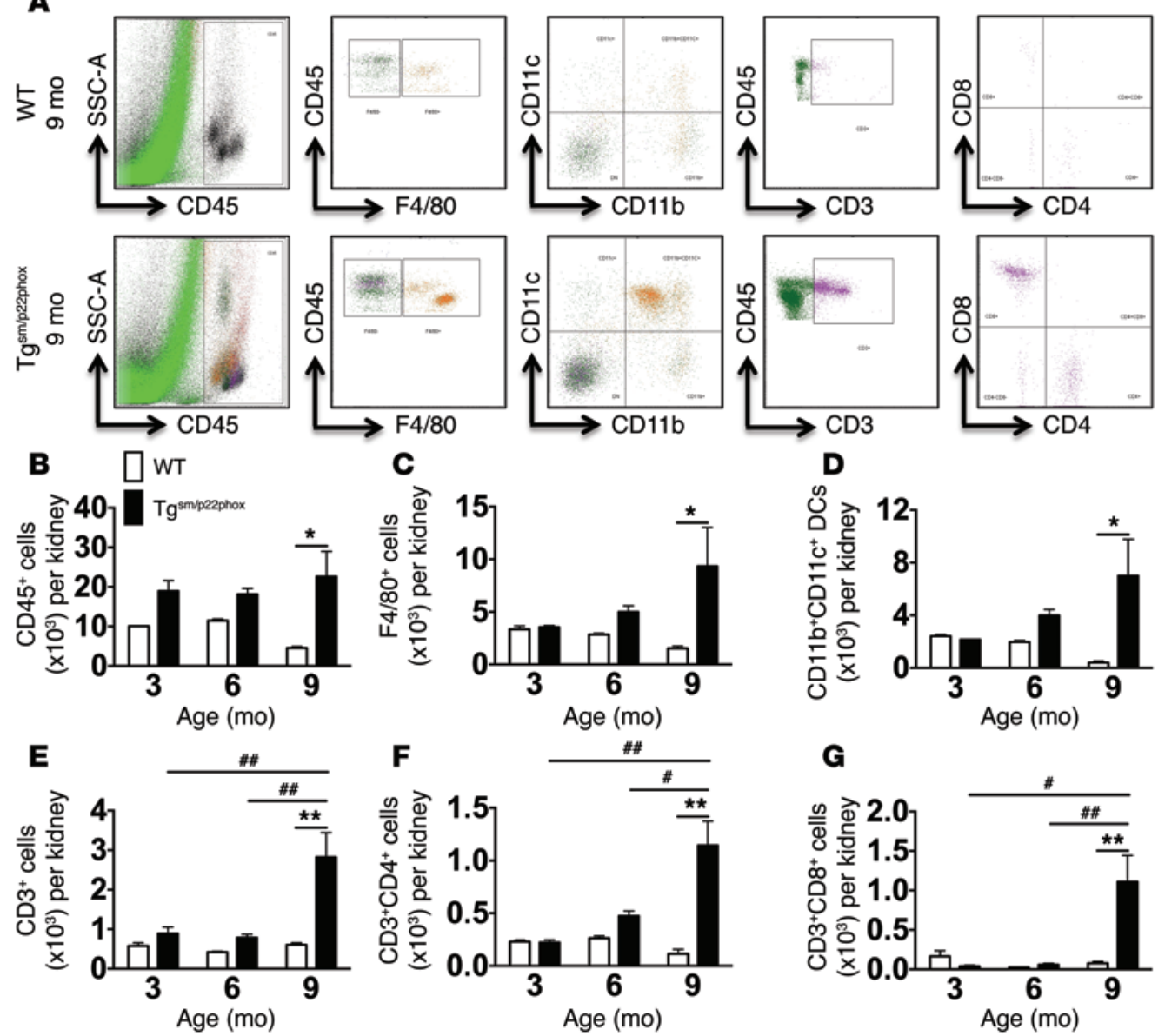

and $\mathrm{G}$ ). To further examine a role of $\mathrm{T}$ cells in aortic stiffening and hypertension in response to vascular oxidative stress, we adoptively transferred $2 \times 10^{7} \mathrm{~T}$ cells to $\mathrm{tg}^{\mathrm{sm} / \mathrm{p} 22 \mathrm{phox}} \times \mathrm{Rag}^{-1^{-/}}$mice at 3 months of age and allowed them to survive until 9 months of age. Adoptive transfer of $\mathrm{T}$ cells restored collagen deposition, aortic stiffening, and blood pressure elevation in the $\operatorname{tg}^{\text {sm/p22phox }} \times$ Rag-1/- $^{-1}$ mice, supporting an essential role of $\mathrm{T}$ cells in the development of aortic fibrosis and hypertension induced by chronic vascular oxidative stress. Likewise, deficiency of Rag-1 protected mice from a decline in their ability to excrete a sodium and volume load at 9 months of age, while this protection was lost in mice that had undergone adoptive transfer of $\mathrm{T}$ cells (Supplemental Figure 4).

Isoketals accumulate in the aorta and antigen presenting cells of $\operatorname{tg} g^{s m / p 22 p h o x}$ mice. Because pyrrole-modified proteins can act as autoantigens and stimulate inflammatory responses $(17,18)$, we sought to determine if chronic vascular oxidant stress promotes their formation. We used stable isotope dilution liquid chromatography/ mass spectrometry (LC/MS) analysis of isoketal-lysyl-lactam to quantify isoketal-protein adducts in thoracic aortic homogenates of 9-month-old mice (Figure 8A, red arrows). Aortic isoketal-protein adducts were markedly elevated in $\operatorname{tg}^{\mathrm{sm} / \mathrm{p} 22 p h o x}$ mice compared with WT mice (Figure 8B). Flow cytometry of single cell suspensions confirmed a higher content of isoketal adducts in CD45- cells of the $\operatorname{tg}^{\mathrm{sm} / \mathrm{p} 22 \mathrm{phox}}$ aortas compared with aortas of WT mice at 3, 6, and 9 months of age. These tended to increase in the transgenic mice, but this did not reach statistical significance (Supplemental Figure 5).
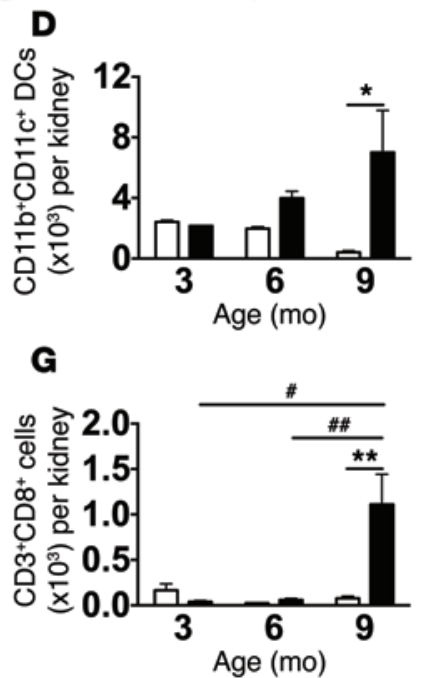

Figure 5. Flow cytometry analysis of renal leukocytes. Single cell suspensions were prepared from freshly isolated mouse kidneys via enzymatic digestion and mechanical dissociation. Live cell singlets were analyzed. (A) CD45 total leukocytes, $\mathrm{F} 4 / 80^{+}$macrophages, CD11 $\mathrm{b}^{+} \mathrm{CD} 11 \mathrm{c}^{+} \mathrm{DCs}, \mathrm{CD}^{+}$ T lymphocytes, and $\mathrm{CD} 4^{+} / \mathrm{CD}^{+}$ $T$ cell subsets were identified in the aorta of 9-month-old WT and

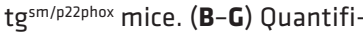
cation of infiltrating leukocyte subsets using 2-way ANOVA $(n=6-8) .{ }^{*} P<0.05 ;{ }^{* *} P<0.01$ $\# P<0.05 ; \# P<0.01$.
To further confirm the presence of isoketal-protein adducts in vessels of $\mathrm{tg}^{\mathrm{sm} / \mathrm{p2} 2 \mathrm{phox}}$ mice, we performed immunohistochemical staining using the single chain antibody D11 (18). Abundant isoketal-protein adducts were identified in aortas of 9-month-old $\operatorname{tg}^{\mathrm{gm} / \mathrm{p} 22 \mathrm{phox}}$ mice but not WT mice (Figure $8 \mathrm{C}$ ). Treatment of mice from 4-9 months of age with either the SOD mimetic tempol or the isoketal scavenging agent 2-hydroxybenzylamine (2-HOBA) eliminated isoketal staining in the $\mathrm{tg}^{\mathrm{sm} / \mathrm{p} 22 \mathrm{phox}}$ mouse vessels.

In additional experiments, we found that isoketals also accumulate in antigen presenting cells (APCs) of $\operatorname{tg}^{\mathrm{sm} / \mathrm{p} 22 \mathrm{phox}}$ mice. Using a recently described gating strategy (25), macrophages were identified as $\mathrm{CD}^{+} 4^{+} \mathrm{MerTK}^{+}$, and DCs were selected from the remaining cells as $\mathrm{CD} 11 \mathrm{c}^{+}$and $\mathrm{MHC}-\mathrm{II}^{+}$cells (Supplemental Figure 6). Monocytes were identified as $\mathrm{CD} 11 \mathrm{~b}^{+} \mathrm{CD} 64^{+} \mathrm{F} 4 / 80^{\text {lo }} \mathrm{SSC}^{\mathrm{lo}}$ cells. Virtually all monocytes were $\mathrm{Ly}-6 \mathrm{C}^{+}$, and most expressed MHC-II. Intracellular staining for isoketals using D11 conjugated to Alexa Fluor 488 revealed that DCs, macrophages, and to a smaller extent monocytes of 9-month-old tg $\mathrm{g}^{\mathrm{sm} / \text { /22phox }}$ mice accumulate isoketal-protein adducts, while cells of age-matched WT animals do not (Figure 8, D-I). This was prevented by chronic treatment with either tempol or 2-HOBA.

We also analyzed the presence of isoketal adducts in peptides eluted from MHC-I using a dot blot analysis and the D11 antibody. Peptides from 9-month-old WT mice were devoid of such adducts; however, those eluted from DCs of aged $\operatorname{tg}^{\text {sm/p22phox }}$ mice were clearly modified by isoketals (Figure 8J). Thus, DCs from mice with chronic vascular oxidative stress present oxidatively modified peptides. 
A
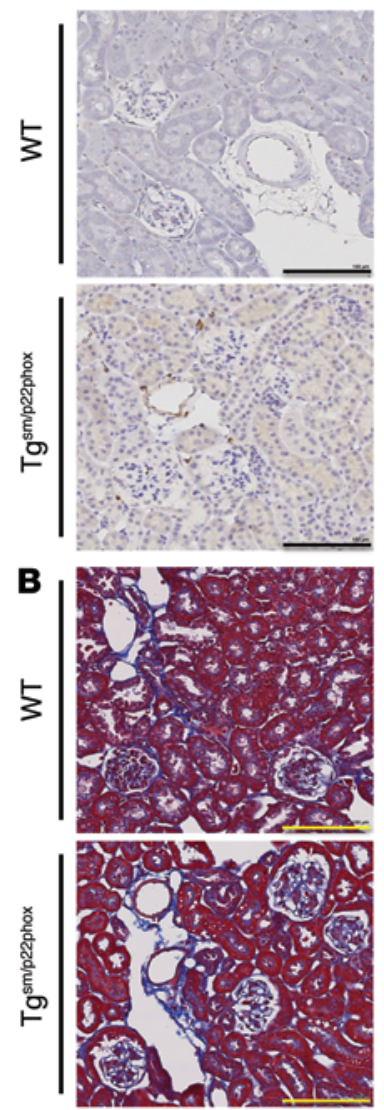

$6 \mathrm{mo}$
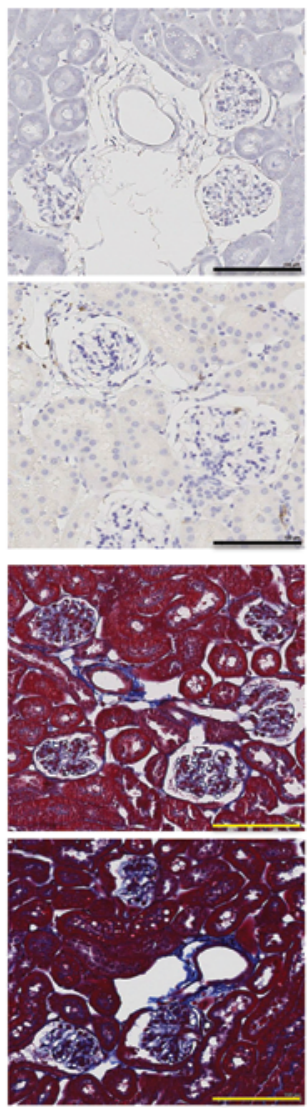

$9 \mathrm{mo}$
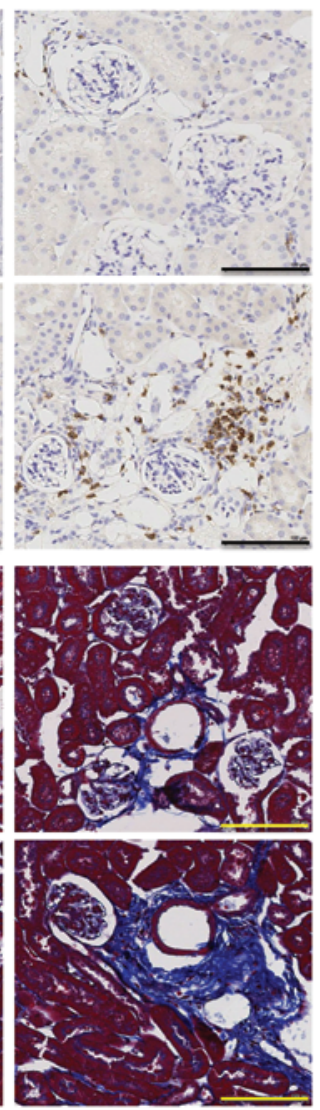

C
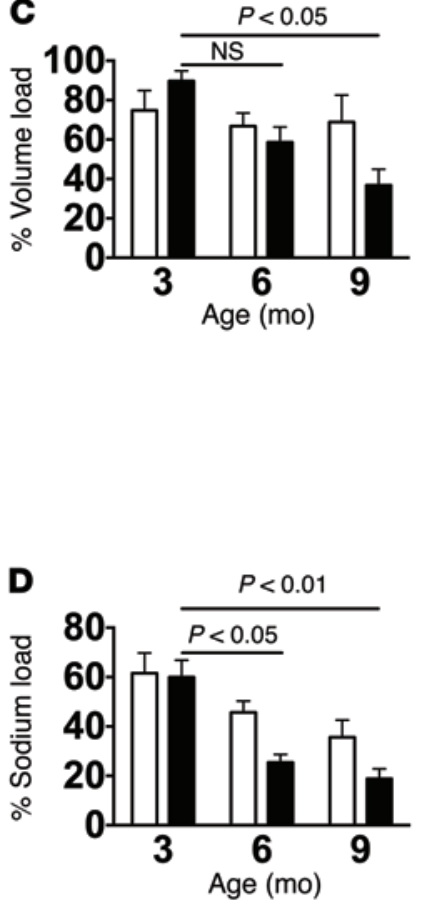

Figure 6. Development of age-related renal inflammation, fibrosis, and dysfunction in $\mathbf{t g}^{\text {sm/p22phox mice. (A and }}$ B) Consecutive 6-micron sections were obtained from paraffin-embedded mouse kidneys and were stained with anti-CD3 and Masson's trichrome blue. Images are $\times 20$ magnification. Scale bars: $100 \mu \mathrm{m}$. (C and D) Mice received a single i.p. injection of normal saline equal to $10 \%$ of body weight, and urine/ sodium excretion in the subsequent 4 hours were monitored. These data were analyzed with 2-way ANOVA $(n=6-8)$.
Scavenging of ROS prevents vascular inflammation, aortic stiffening, renal dysfunction, and hypertension in $\operatorname{tg}^{\text {sm/p22phox }}$ mice. To determine if scavenging superoxide or isoketals prevents vascular oxidative stress-induced aortic stiffening and hypertension, we treated mice with either tempol or 2-HOBA from 4-9 months of age and monitored blood pressure with telemetry. Both of these therapies prevented aortic fibrosis in $\operatorname{tg}^{\mathrm{sm} / \mathrm{p} 22 \mathrm{phox}}$ mice at 6 and 9 months of age (Figure 9, A-C). Similarly, treatment with either tempol or 2-HOBA prevented aortic stiffening and age-related hypertension (Figure 9, D-G). Treatment with either tempol or 2-HOBA also preserved the ability to excrete a sodium and volume challenge at 9 months of age (Supplemental Figure 7). These data support a role of vascular ROS in promoting vascular fibrosis, aortic stiffening, and age-related hypertension. Despite the effectiveness of tempol and 2-HOBA in preventing aortic stiffening and hypertension, we found that these agents did not reverse these abnormalities if introduced at 7 months of age (Supplemental Figure 8).

To determine if superoxide or isoketal scavenging reduced vascular inflammation, we performed flow cytometry on the aortas of $\operatorname{tg}^{\text {sm/p22phox }}$ mice treated with vehicle, tempol, or 2-HOBA from 4-9 months of age. Both tempol and 2-HOBA markedly reduced the aortic infiltration of leukocytes (Figure 10, A-C). The infiltrating $\mathrm{CD}^{2} 5^{+}$total leukocytes, $\mathrm{F} 4 / 80^{+}$monocyte/macrophages, $\mathrm{CD} 19^{+} \mathrm{B}$ cells, $\mathrm{CD}^{+}$total $\mathrm{T}$ cells, and $\mathrm{CD} 4^{+}$and $\mathrm{CD}^{+} \mathrm{T}$ cell subsets were significantly reduced by either of these treatments (Figure 10, D-I).

Vascular oxidative stress promotes cytokine production by splenic $T$ cells. We and others have previously shown that IL-17A and IFN- $\gamma$ contribute to hypertension $(14,16,26)$ and that IL-17A plays a critical role in aortic stiffening (15). We therefore sought to determine if $\mathrm{T}$ cells of mice with vascular oxidative stress produce IL-17A and IFN- $\gamma$. Splenic T cells from 9-month-old WT and $\operatorname{tg}^{\text {sm/p22phox }}$ mice were analyzed by flow cytometry using intracellular staining for these cytokines (Figure 11A). While WT T cells produced minimal amounts of IL-17A, $5 \%$ of $\mathrm{CD}^{+} \mathrm{T}$ cells and $10 \%$ of double-negative $\left(\mathrm{CD}^{+} /\right.$ $\mathrm{CD}^{-} / \mathrm{CD}^{-}$) $\mathrm{T}$ cells of $\mathrm{tg}^{\mathrm{sm} / \mathrm{p} 22 \mathrm{phox}}$ mice produced this cytokine (Figure $11, \mathrm{~B}$ and $\mathrm{D}-\mathrm{F}$ ). Likewise, IFN- $\gamma$-producing cells were doubled in all 3 subsets of T lymphocytes in $\mathrm{tg}^{\mathrm{sm} / \mathrm{p} 22 \mathrm{phox}}$ mice compared with WT (Figure 11, C and G-I). Treatment with tempol or 2-HOBA normalized $\mathrm{T}$ cell production of IL-17A and IFN- $\gamma$ in $\mathrm{tg}^{\mathrm{sm} / \mathrm{p} 22 \mathrm{phox}}$ mice. These data suggest that vascular oxidative stress systemically activates $\mathrm{T}$ cells and promotes their proinflammatory cytokine production.

Protein homogenates of $\mathrm{tg}^{\mathrm{sm} / \mathrm{p2} 2 \mathrm{phox}}$ mouse vessels are immunogenic. We have shown that isoketal-protein adducts promote maturation and activation of DCs in angiotensin II-induced hypertension and that these activated DCs can drive proliferation of $\mathrm{T}$ cells from angiotensin II-treated mice (18). To determine if proteins from the aortas of $\mathrm{tg}^{\mathrm{sm} / \mathrm{p} 22 \mathrm{phox}}$ mice are immunogenic, we prepared aortic homogenates from WT and $\mathrm{tg}^{\mathrm{sm} / \mathrm{p} 22 \text { phox }}$ mice at 9 months of age. These were used to pulse naive DCs from WT mice for 2 hours and were then washed from the cells (Figure 12A). The pulsed DCs were then cocultured with $1 \times 10^{7} \mathrm{~T}$ cells isolated from the spleen of either WT or $\operatorname{tg}^{\mathrm{sm} / \mathrm{p} 22 \text { phox }}$ mice and prelabeled with CFSE at a ratio of 1:10. Of note, $\mathrm{T}$ cells isolated from $\operatorname{tg}^{\mathrm{sm} / \mathrm{p} 22 \text { phox }}$ mice, but not those from WT mice, survived and proliferated in response to the stimulation of immunogenic protein homogenate of $\mathrm{tg}^{\mathrm{sm} / \mathrm{p} 22 \mathrm{phox}}$ mice, suggesting that preexposure to isoketal-adducted antigens in vivo 
A WT

$\operatorname{Tg}^{\text {smp22phox }}$

$\operatorname{Tg}^{\text {smp22phox }} \times R^{2}$ ag-1-1

$\mathrm{Tg}^{\text {sm/p22phox }} \times$ Rag-1-1- $^{-1}$

+ pan $T$ cells
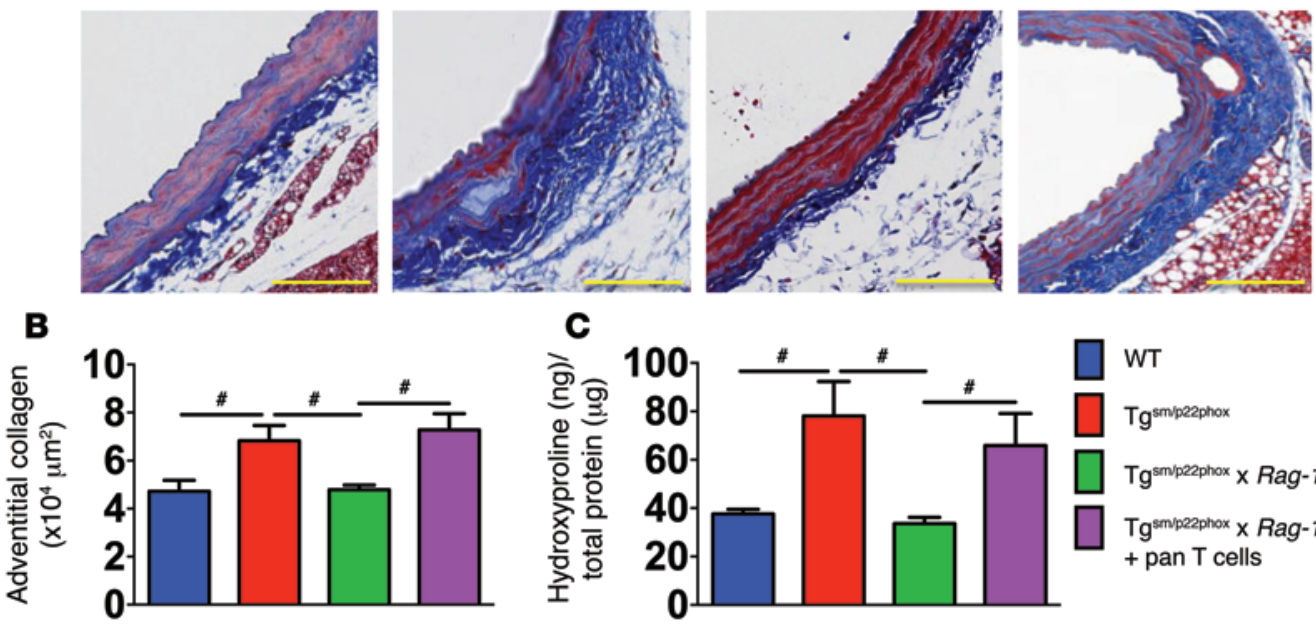

C
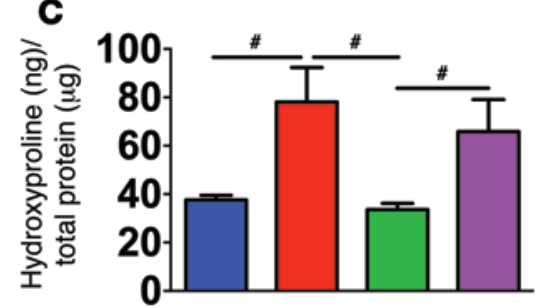

WT

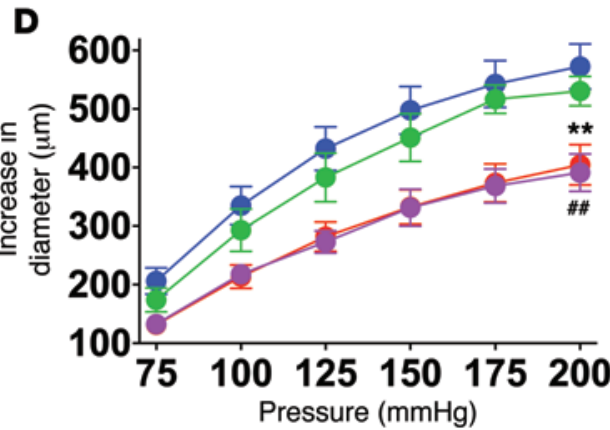

E
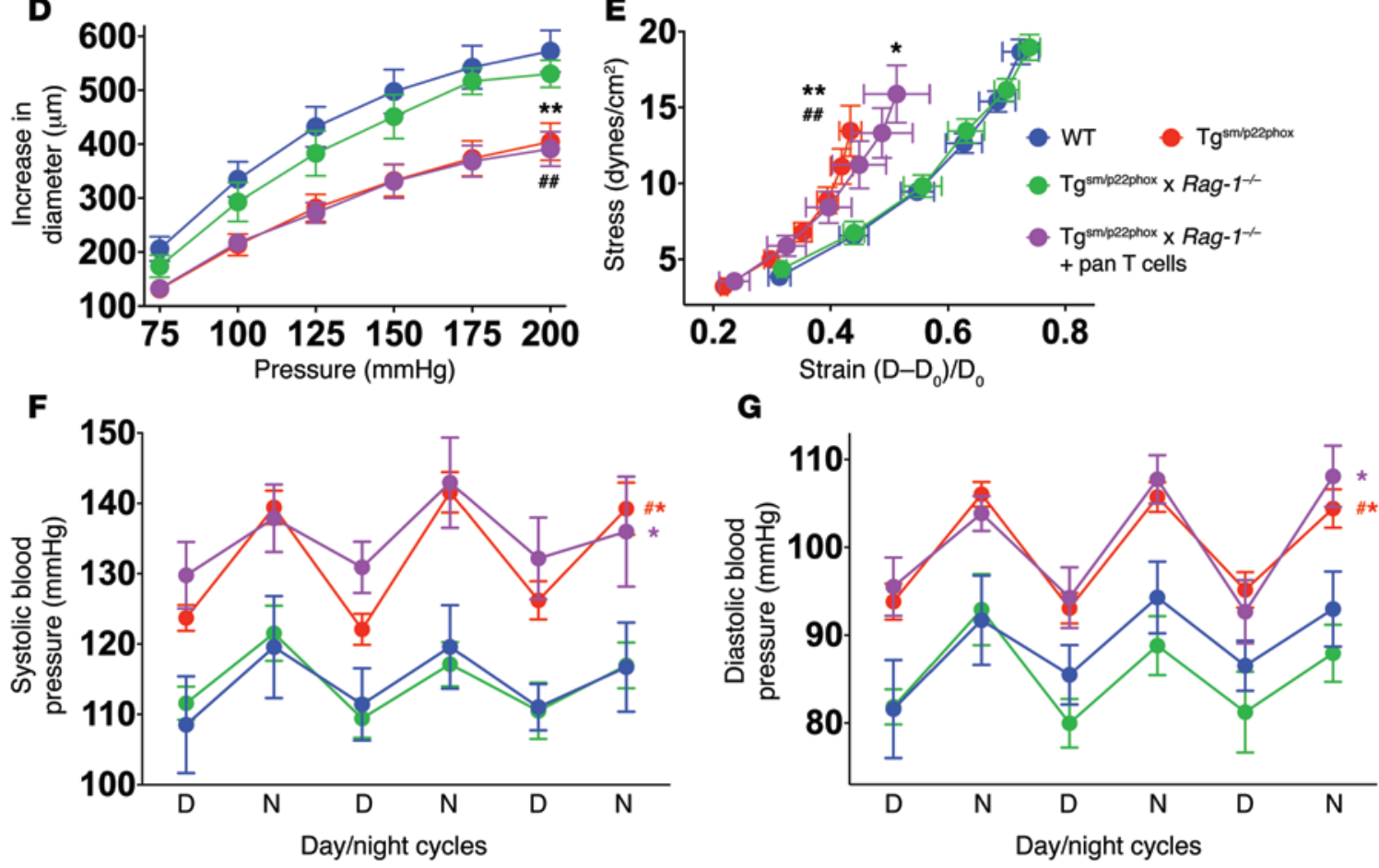

Figure 7. T cells mediate age-related aortic collagen deposition, aortic stiffening, and elevation of blood pressure in tg ${ }^{\mathrm{sm} / \mathrm{p22phox}} \mathbf{m i c e}^{\mathrm{ic}}$. Pan $\mathrm{T}$ cells were

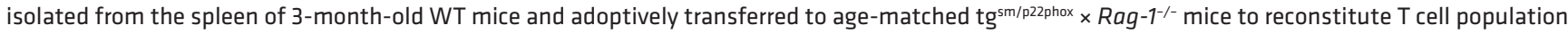
Mice were subsequently studied at 9 months of age. (A) Examples of aortic Masson's trichrome blue staining. (B) Quantification of collagen staining by planimetry. (C) Quantification of aortic hydroxyproline levels. ${ }^{\#} P<0.05$. (D and E) Pressure diameter curves and stress strain relationships obtained using

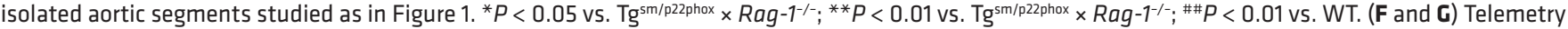
recordings of blood pressures over 3 days. $\# P<0.05$ vs. WT. Collagen deposition was quantified using 1 -way ANOVA. Aortic stiffness and blood pressure were analyzed using 1-way ANOVA with repeated measures $(n=6-8)$.

primed these cells for clonal expansion upon a second challenge (Figure 12, B-I). Aortic homogenates of $\operatorname{tg}^{\mathrm{sm} / \mathrm{p} 22 \mathrm{phox}}$ mice, but not WT mice, supported survival of $\mathrm{CD}^{+}$(Figure 12, B and F), $\mathrm{CD}^{+}$, and $\mathrm{CD}^{+} \mathrm{T}$ cells (Figure 12, $\mathrm{C}$ and $\mathrm{G}$ ) when presented to $\mathrm{T}$ cells by DCs. DCs pulsed with $\mathrm{tg}^{\mathrm{sm} / \mathrm{p} 22 \mathrm{phox}}$ aortic homogenates also induced proliferation of $\mathrm{CD}^{+}$(Figure 12, D and $\mathrm{H}$ ) and to a lesser extent $\mathrm{CD} 8^{+}$ $\mathrm{T}$ cells (Figure 12, $\mathrm{E}$ and I), and increased the release of IL-17A/F, IFN- $\gamma$, and TNF- $\alpha$ into the medium (Table 1). Chronic treatment of $\operatorname{tg}^{\mathrm{sm} / 222 \mathrm{phox}}$ mice with tempol or 2-HOBA reduced the immunogenic- ity of their aortic protein, as indicated by the diminished survival, proliferation, and cytokine production of $\mathrm{T}$ cells in this assay.

To determine if DCs were functionally activated in these conditions, we also evaluated the polarizing cytokines released into the medium. When DCs exposed to $\operatorname{tg}^{\mathrm{sm} / \text { p22phox }}$ aortic homogenates were cocultured with $\mathrm{T}$ cells isolated from $\operatorname{tg}^{\mathrm{sm} / \mathrm{p} 22 \mathrm{phox}}$ mice, there was a marked increase of GM-CSF, IL-1 $\alpha$, IL-1 $1 \beta$, IL- 6 , TGF- $\beta 1$, and TGF- $\beta 3$ (Table 1). These increases were blunted when DCs were primed with aortic homogenates from $\operatorname{tg}^{s \mathrm{sm} / 222 \mathrm{phox}}$ mice chronically 
A
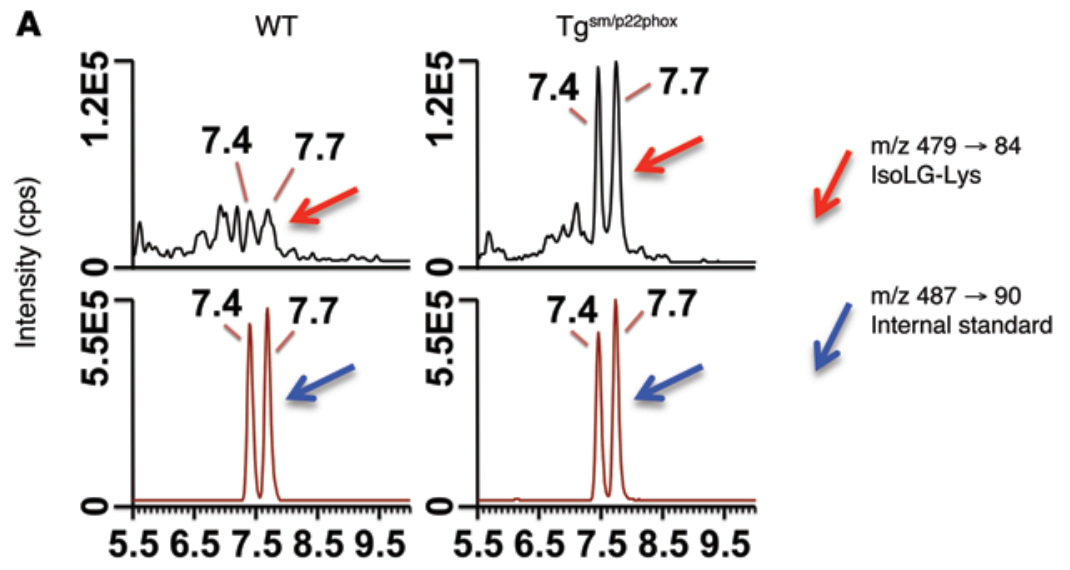

B
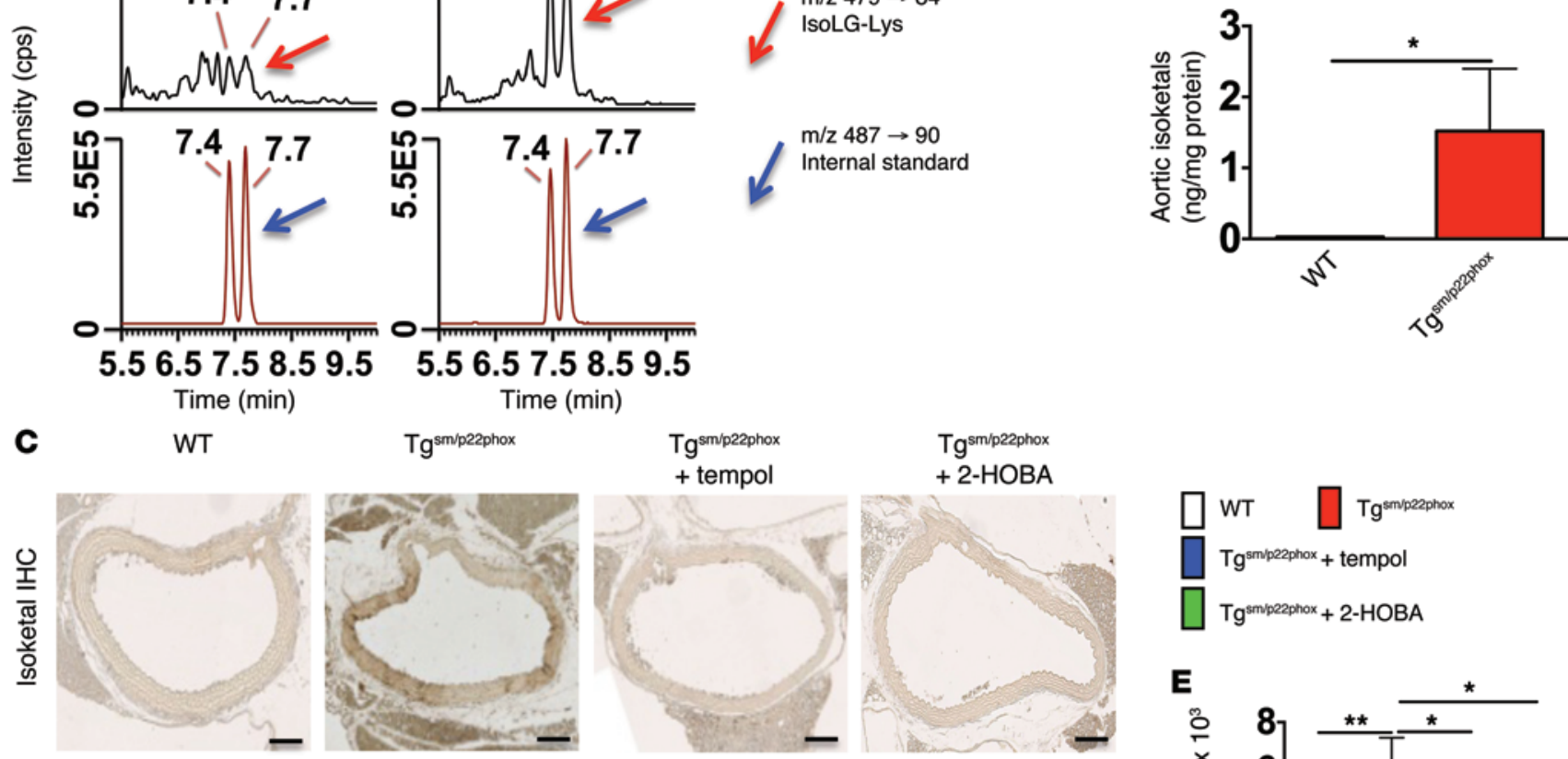

Time ( $\mathrm{min})$
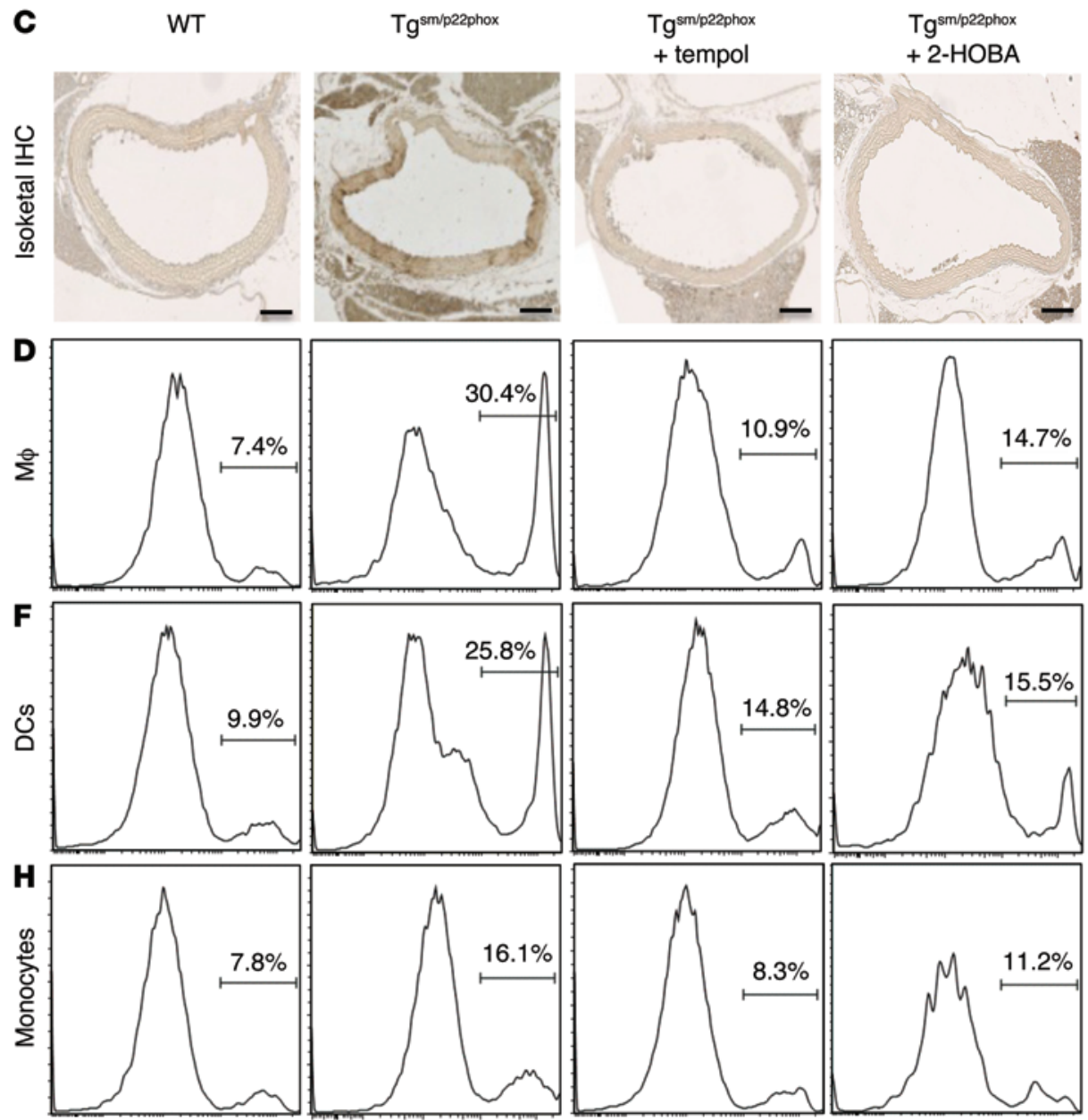

\section{D11 ScFv anti-isoketal}
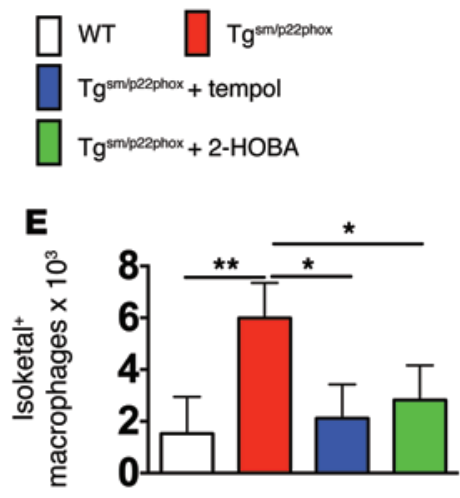

Figure 8. Chronic vascular oxidative stress promotes isoketal-adduct formation. (A and B) Stable isotope dilution multiple reactions monitoring MS analysis of isoketal-lysine-lactam (IsoK-Lys) adducts in aortas of 9-month-old animals. Representative LC/MS chromatographs from pooled samples for each group (A). The left panel shows chromatographs for IsoK-Lys in samples, while the right panel shows chromatographs for $\left[{ }^{13} \mathrm{C}_{6}{ }^{15} \mathrm{~N}_{2}\right]$ internal standards in the same samples. Mann-Whitney tests were employed for analysis. The bar graph in B shows mean data. (C) Fix-perfused mouse aortas were embedded in paraffin and subjected to IHC for isoketal staining. Images are $\times 20$ magnification. Scale bars: $100 \mu$ m. (D-I) Intracellular staining for isoketals in spleen macrophages ( $\mathbf{D}$ and $\mathbf{E}), \mathrm{DCs}$ (F and $\mathbf{G})$, and monocytes (H and I). These data were analyzed using 1 -way ANOVA, $n=6$. ${ }^{*} P<0.05$; ${ }^{* *} P<0.01$. (J) DCs isolated from 9-month-old WT and $\mathrm{tg}^{\text {sm/p22phox }}$ mice were exposed to weak acid to elute peptides presented on MHC-I complexes. The presence of isoketal-adducted peptides in the eluent was visualized by dot blot. Isoketal adducts were present in 3 of $4 \mathrm{tg}{ }^{\mathrm{sm} / \mathrm{p} 22 \mathrm{phox}}$ mice but not in WT mice (see Supplemental Figure 5C for full uncut gel). 
A

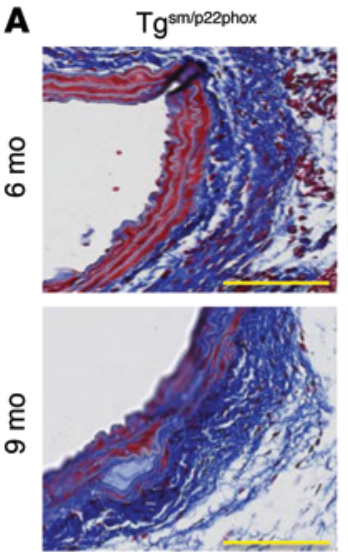

$\mathrm{Tg}^{\text {smp22phox }}+$ tempol

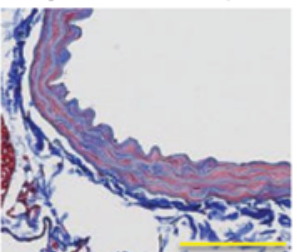

$\mathrm{Tg}^{\text {smp22phox }}+2$-HOBA
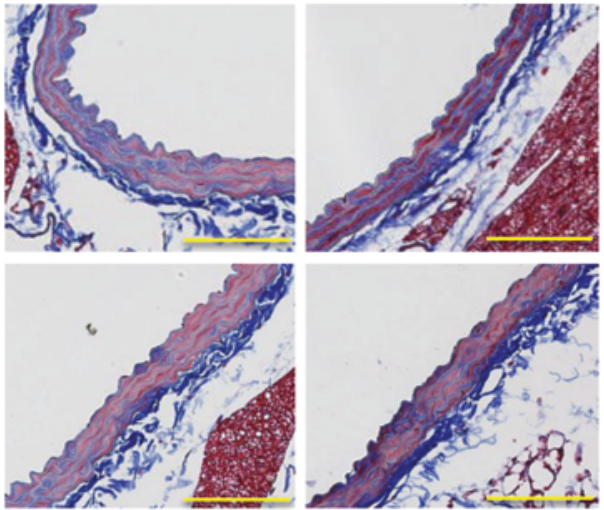

- Tgempezphox $9 \mathrm{mo}$

- Tg ${ }^{\text {sm/p2zphox }} 9$ mo + tempol

C
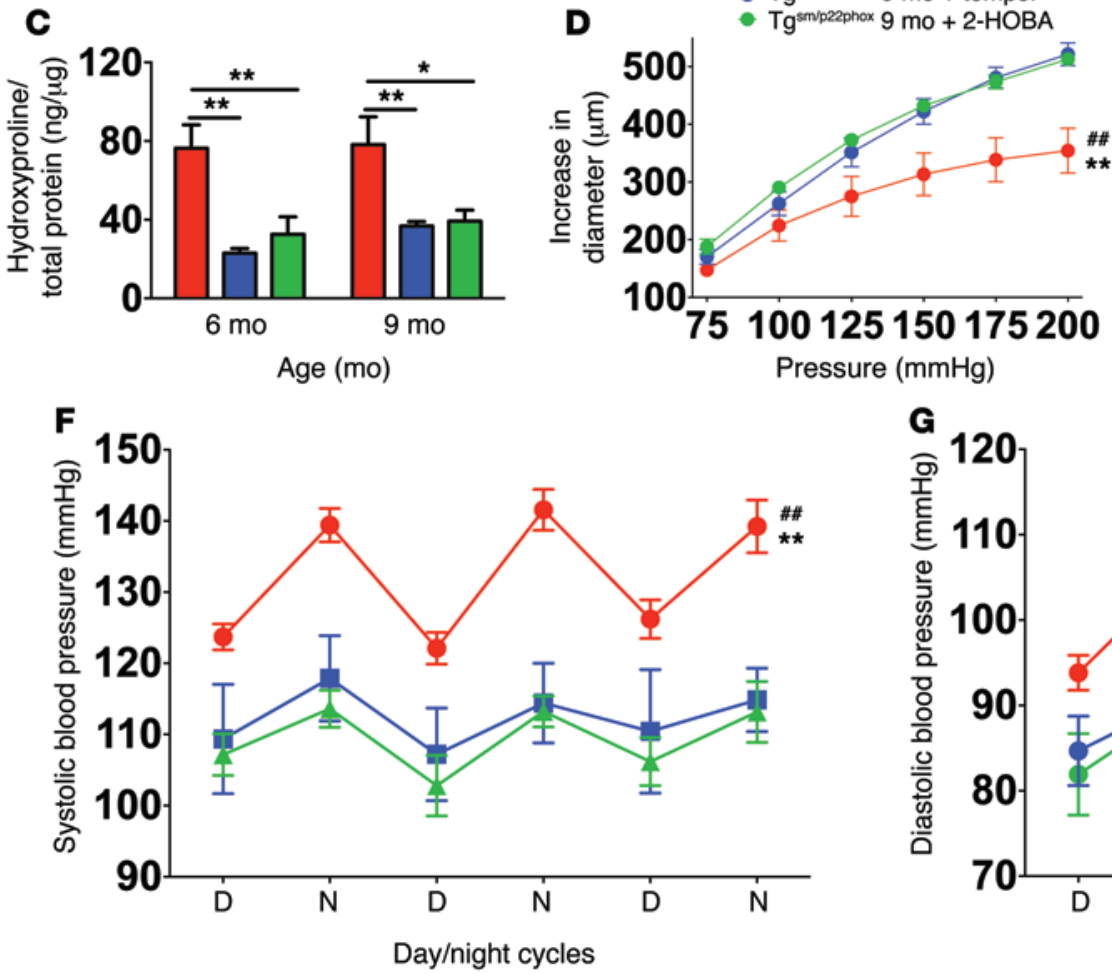

B
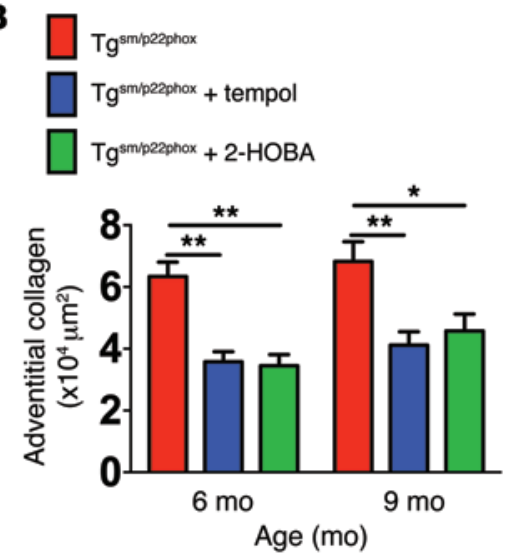

E

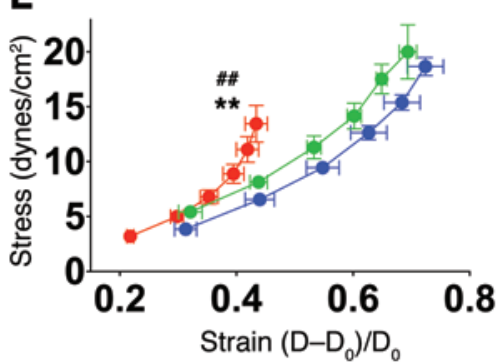

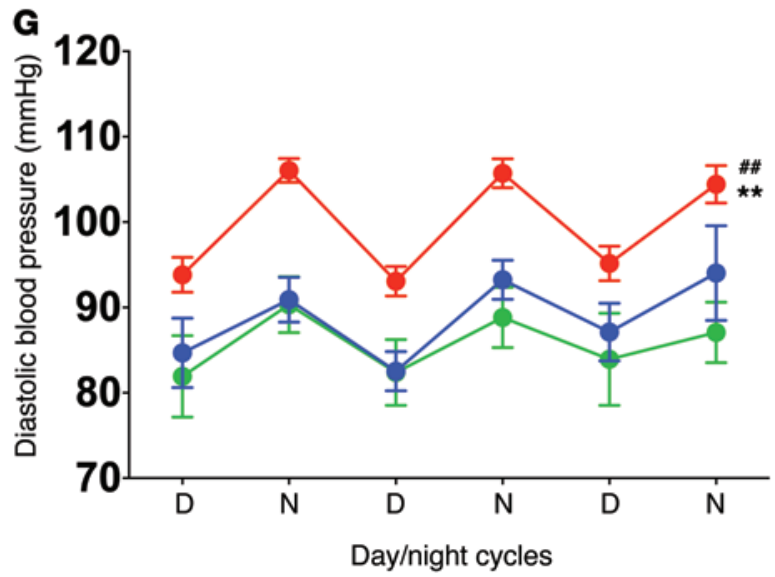

Figure 9. Scavenging superoxide or isoketals prevents aortic collagen deposition, aortic stiffening and hypertension in $\mathbf{t g}^{\mathrm{sm} / \mathrm{p}^{22 p h o x}} \mathbf{m i c e}^{\mathrm{ic}} \mathrm{Tg}^{\mathrm{sm} / \mathrm{p2}^{2} \mathrm{phox}} \mathrm{mice}$ received either no treatment, tempol, or 2-HOBA in the drinking water from 3-9 months of age. (A) Masson's trichrome staining at $\times 20$ magnification. Scale bars: $100 \mu \mathrm{m}$. (B and C) Mean data for quantification of collagen staining (B) and hydroxyproline content (C). ${ }^{*} P<0.05$; ${ }^{* *} P<0.01$. (D and E) Pressure

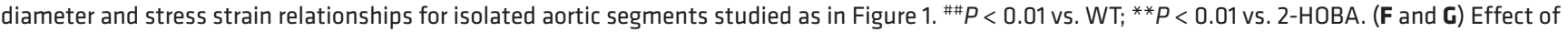
antioxidant treatment on blood pressure in aged $\mathrm{tg}^{\text {sm/p2zphox }}$ mice. Collagen deposition was quantified using 1-way ANOVA. Aortic stiffness and blood pressure were analyzed with 1-way ANOVA with repeated measurements $(n=6-8)$.

treated with tempol or 2-HOBA, suggesting that superoxide and isoketals contribute to immunogenicity of vascular proteins. Interestingly, $\operatorname{tg}^{\mathrm{sm} / \mathrm{p} 22 \mathrm{phox}}$ mouse aortic homogenates failed to induce DCs to produce these cytokines if they were cocultured with $\mathrm{T}$ cells from WT mice, suggesting that interactions with isoketal-primed T cells also promote DC activation. Other cytokines - such as IL-2, IL-12 (p40), IL-12 (p70), IL-21, IL-23, and TGF- 32 - were either undetectable or not differentially produced across treatment groups.

Evidence that the isoprostane/isoketal pathway contributes to aortic stiffening and inflammation in humans. To determine if our findings in mice have relevance to humans, we performed 2 addi- tional studies. First, we examined the degree of fibrosis and the presence of isoketal adducts and T cells in sections of human aortas using staining with Masson's trichrome, D11, and anti-CD3, respectively. Unlike mouse vessels, human aortas were often noted to contain collagen and $\mathrm{T}$ cells not only in the adventitia, but also in the media (Figure 13A). Despite this difference in species, we found that the severity of fibrosis was significantly correlated with the presence of isoketal adducts (Figure 13, A and B) and T cells (Figure 13, A and C) in human aortas. Additionally, there was also correlation between the presence of $\mathrm{T}$ cells and isoketal adducts (Figure 13, A and D). 
A
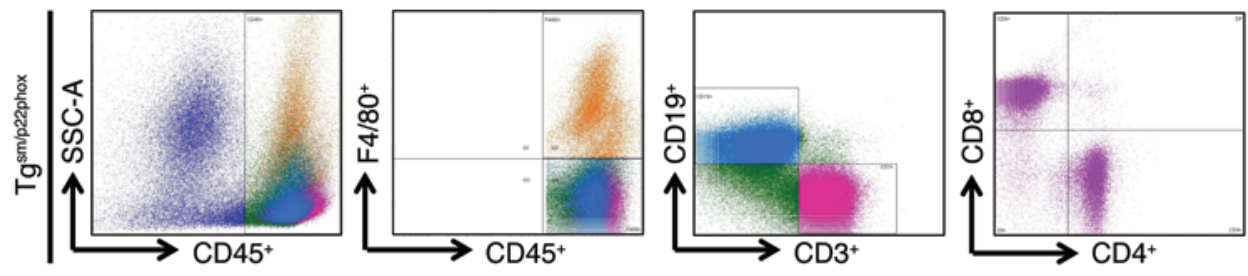

B
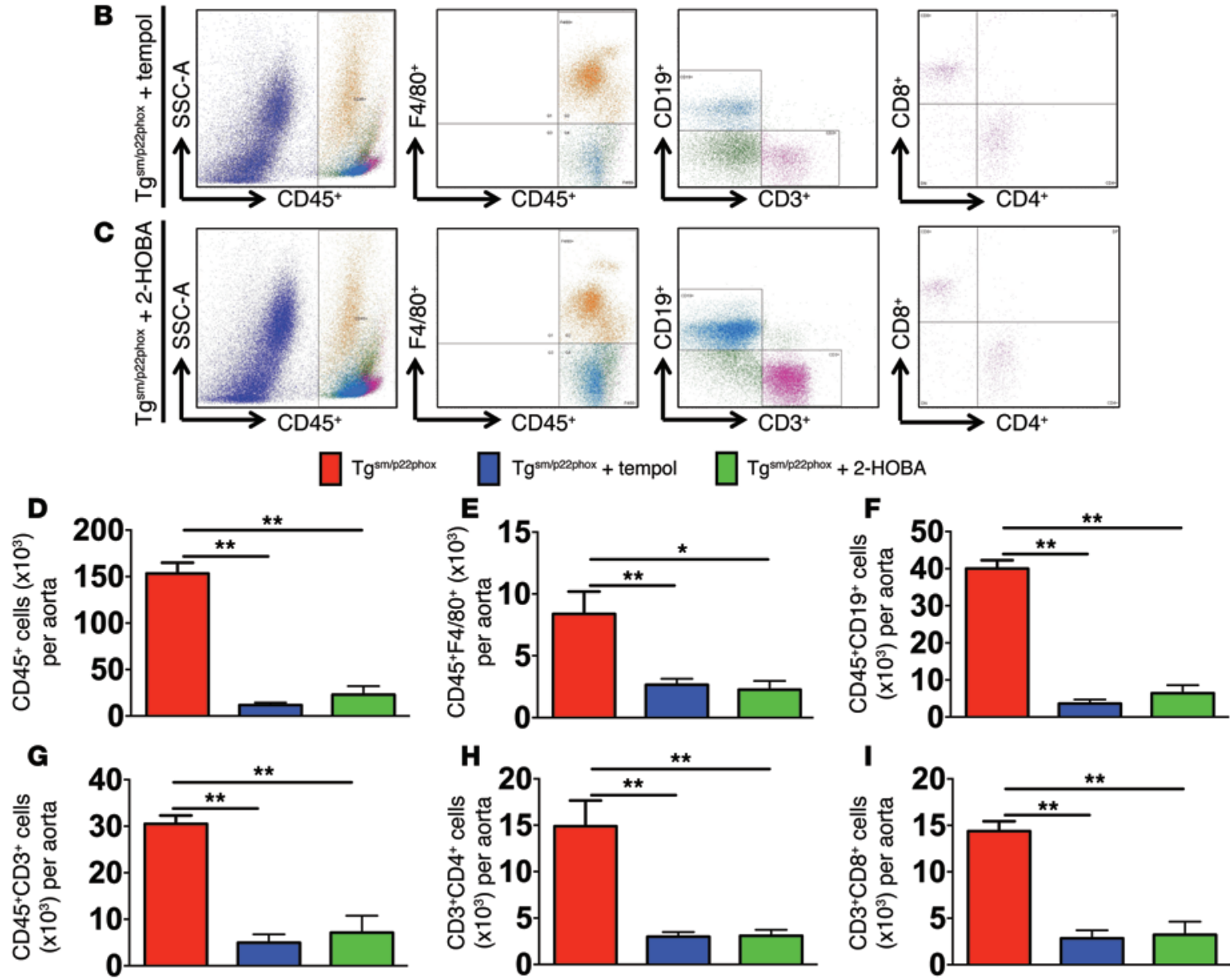

Figure 10. Role of ROS and isoketals in vascular inflammation. Tg ${ }^{\text {sm/p22phox }}$ mice were treated with tempol or 2-HOBA from 4-9 months of age. (A-C) Flow cytometric examples for leukocytes measured in single cells suspensions of aortas. (D-I) Mean data analyzed using $1-$ way ANOVA ( $n=6-8)$. $P<0.05 ;{ }^{* *} P<0.01$.

Because isoketals are formed upon spontaneous rearrangement of isoprostanes, we performed an additional study in which we measured plasma levels of $\mathrm{F}_{2}$-isoprostanes in 15 normotensive subjects and 28 patients with well-controlled hypertension. The general characteristics of these subjects are shown in Table 2. Age, $\mathrm{BMI}$, fasting glucose, $\mathrm{HbA1C}$, and systolic blood pressure were greater in the patient group than with the normotensive volunteers. Subjects in the hypertensive group were receiving between 2 and 4 antihypertensive agents, including diuretics, calcium channel blockers, angiotensin I-converting enzyme inhibitors, angiotensin type 1 receptor antagonists, and $\beta$-blockers. Overall, the hypertensive patients had increased levels of plasma $\mathrm{F}_{2}$-isoprostanes compared with normotensive subjects $(10.7 \pm 1.6 \mathrm{ng} / \mathrm{ml}$ vs. $17.7 \pm 2.2 \mathrm{ng} / \mathrm{ml}$, $P<0.05$, Table 2). Importantly, there was highly significant correlation between levels of plasma $\mathrm{F}_{2}$-isoprostanes and PWV for the entire cohort (Figure 13E), and this remained significant after adjusting for age, BMI, fasting glucose, and systolic blood pressure (Table 3).

\section{Discussion}

Our present study defines a new pathway in which vascular oxidative stress promotes systemic inflammation via formation of immunogenic isoketal-protein adducts. These act as autoantigens that are presented to $\mathrm{T}$ lymphocytes by APCs, leading to $\mathrm{T}$ cell activation. These activated $\mathrm{T}$ cells then infiltrate the vascular adventitia and release cytokines that induce collagen deposition, leading to aortic stiffening, renal inflammation and dysfunction, and ultimately hypertension (Figure 14). Aortic stiffening accompanies several common conditions, including aging, hypertension, atherosclerosis, overt diabetes, obesity, and cigarette smoking (5, 27-29). In many of these conditions, vascular oxidative stress is known to exist and might initiate the pathway delineated in this study.

A recent analysis of the Framingham population indicates that aortic stiffening precedes development of overt hypertension (3). In this regard, the $\operatorname{tg}^{\mathrm{sm} / \mathrm{p} 22 \mathrm{phox}}$ mouse recapitulates this sequence of events. At 6 months, aortic compliance is reduced in these ani- 
A
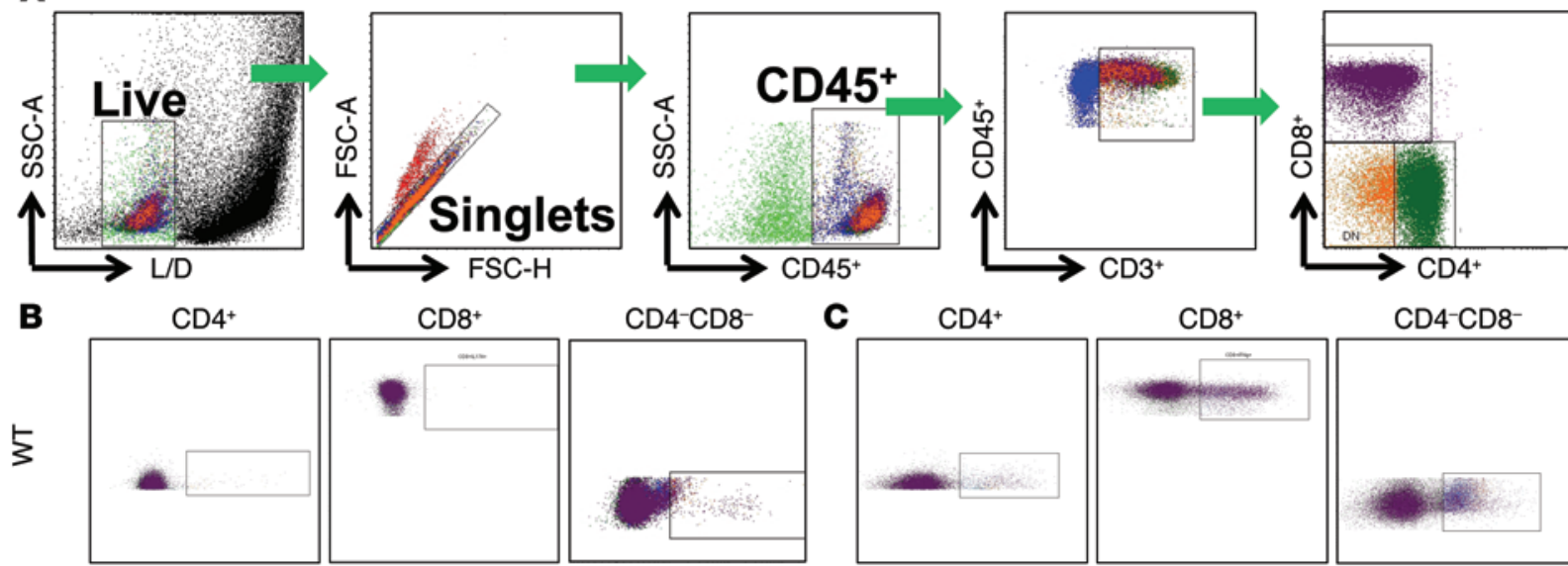

C $\mathrm{CD}^{+}$

$\mathrm{CD}^{+}$
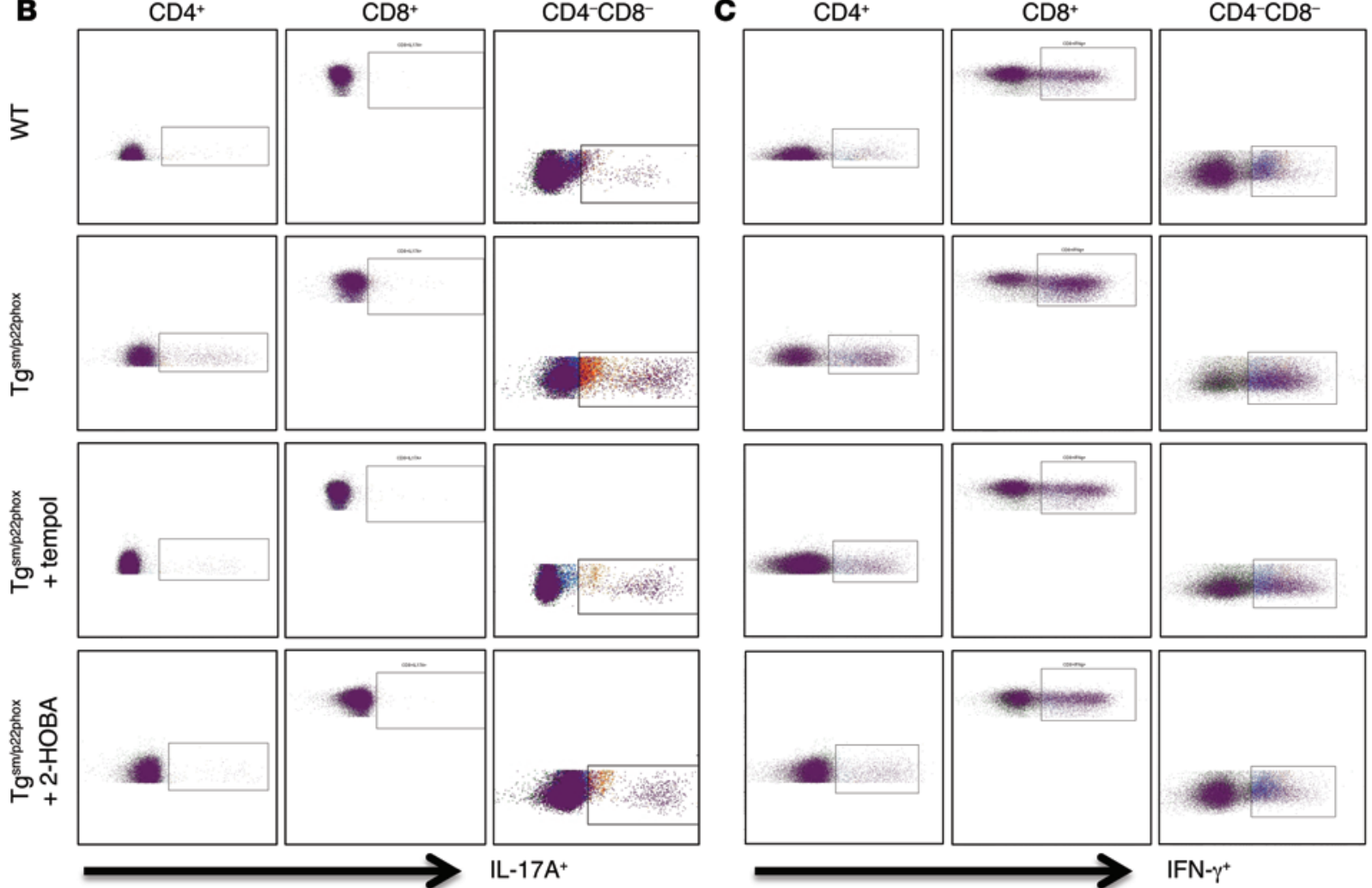

IL-17A ${ }^{+}$
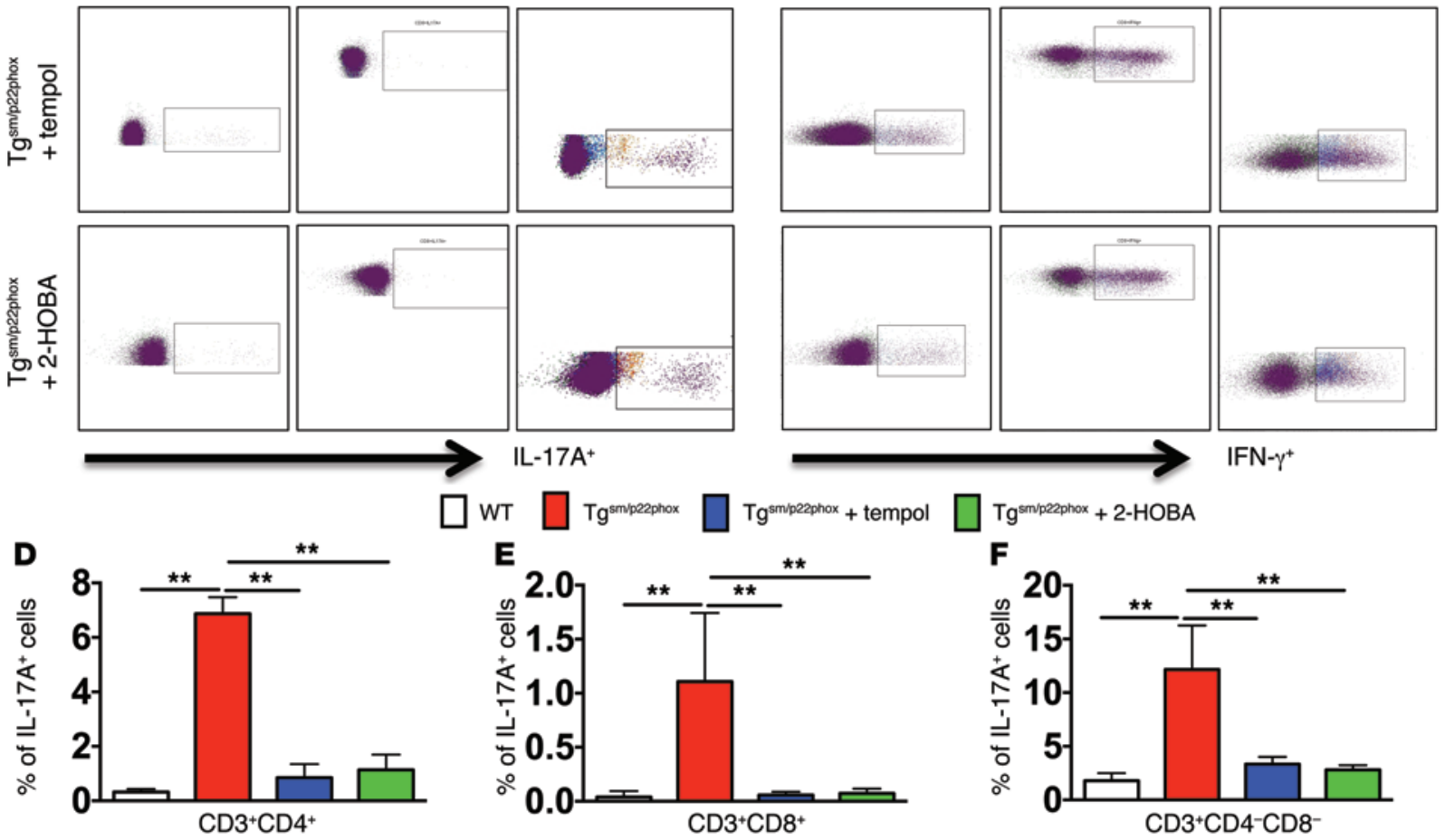

$\square$ WT
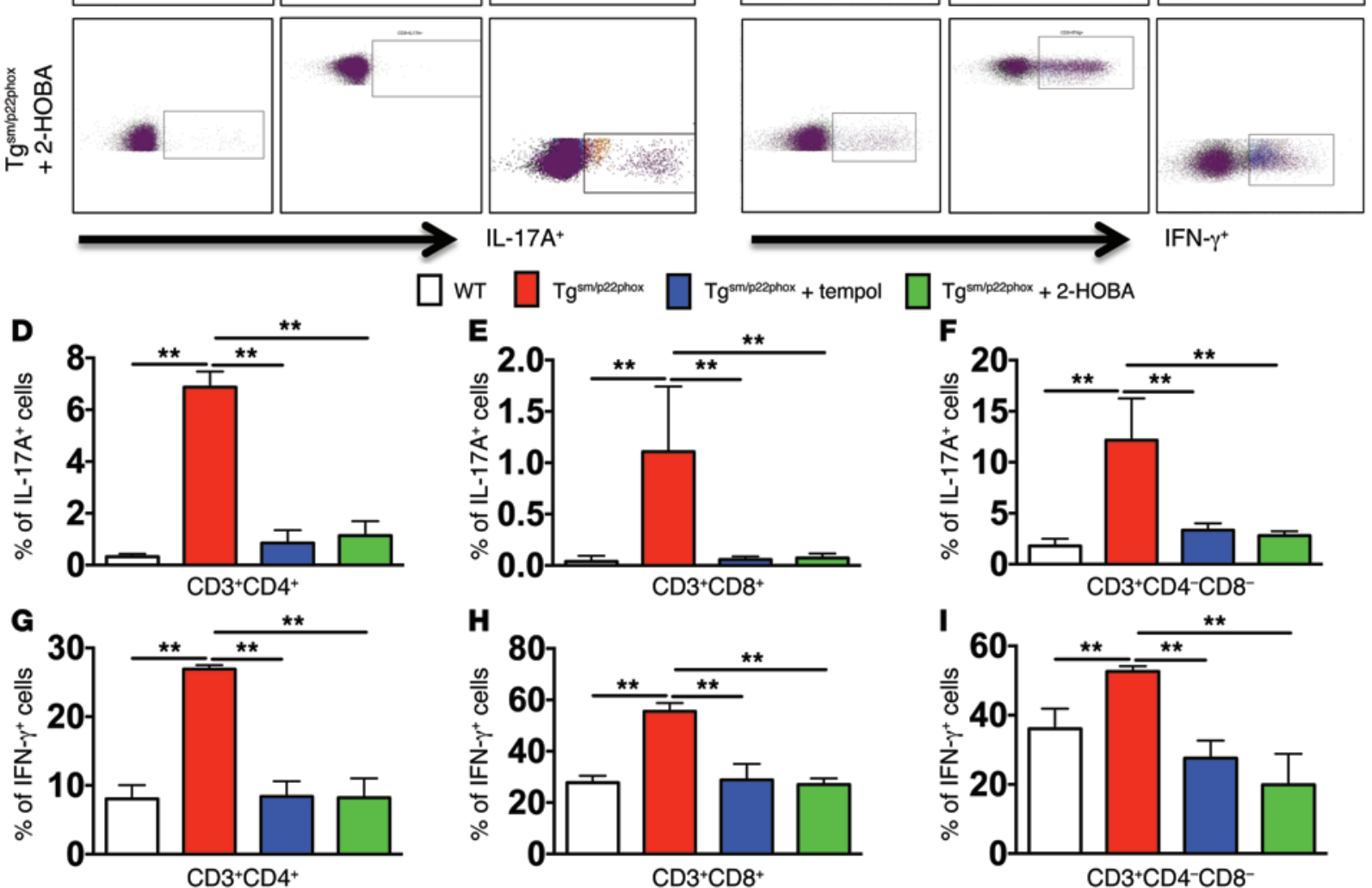

Figure 11. Cytokine production of $T$ cells in the spleen of mice with chronic vascular oxidative stress. (A) Gating strategy for identifying $T$ cell populations among total spleenocytes. Single cell suspensions were prepared from freshly isolated mouse spleens via enzymatic digestion and mechanical dissociation. (B-I) Intracellular staining indicating IL-17A (B, D-F) and IFN- $\gamma(\mathbf{C}, \mathbf{G}-\mathbf{I})$ production in T cell subsets in WT and Tg ${ }^{\mathrm{sm} / \mathrm{p2} 2 \mathrm{phox}}$ mice. Bar graphs were analyzed using 1-way ANOVA $(n=5-7)$. ${ }^{* *} P<0.01$. 
A

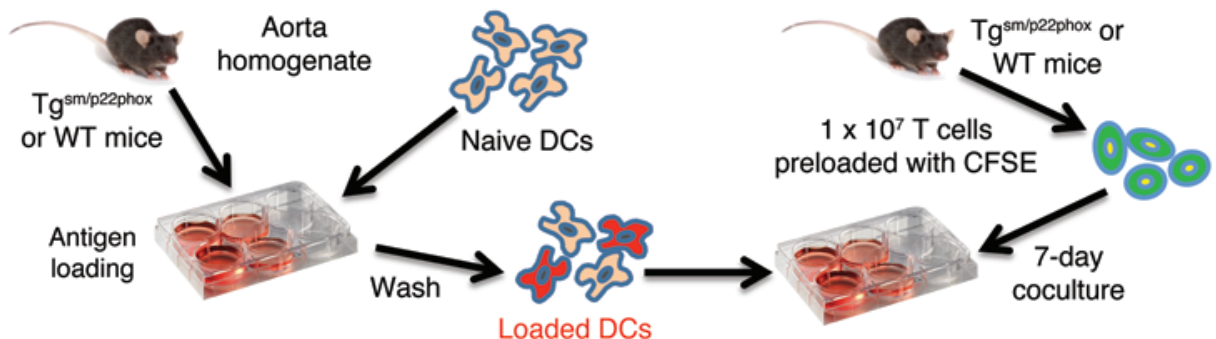

\begin{tabular}{|c|c|c|c|c|c|c|}
\hline $\begin{array}{l}\text { Aorta } \\
\text { homo. }\end{array}$ & W & WT & $\operatorname{Tg}^{\text {sm/p22phox }}$ & $\mathrm{Tg}^{\text {sm/p22phox }}$ & $\begin{array}{l}\mathrm{Tg}^{\text {sm/p2zphox }} \\
+ \text { tempol }\end{array}$ & $\begin{array}{l}\mathrm{Tg}^{\text {sm/p22phox }} \\
+2-\mathrm{HOBA}\end{array}$ \\
\hline
\end{tabular}

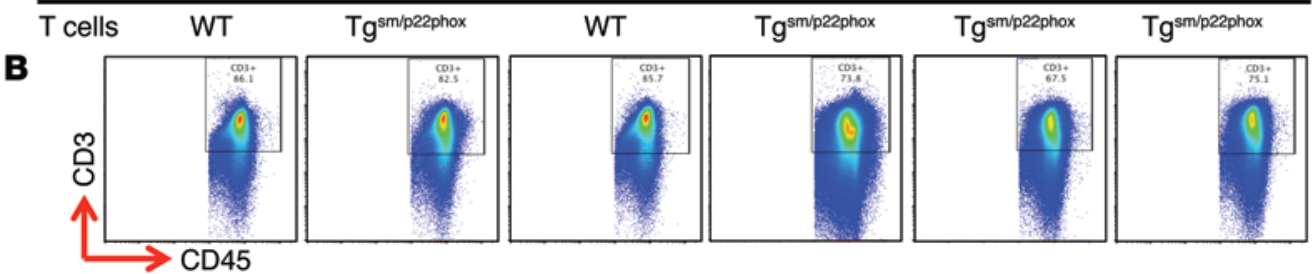

C

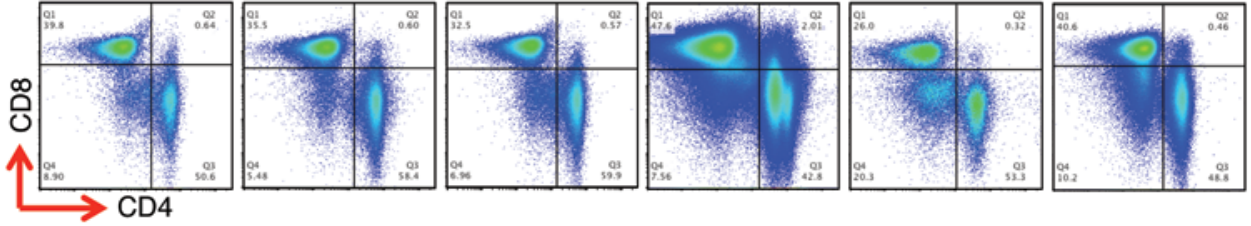

D
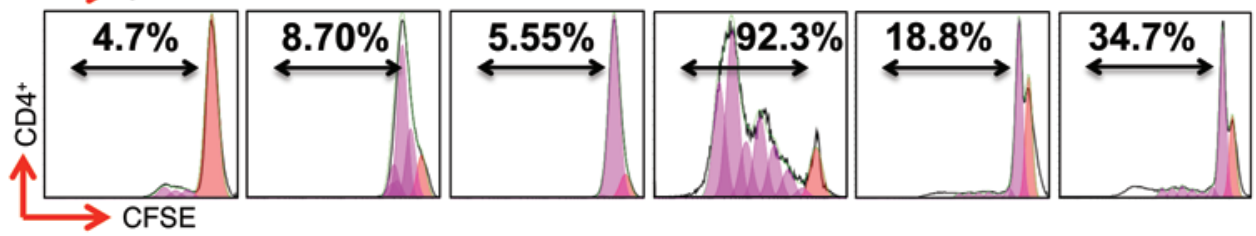

$\mathbf{E}$
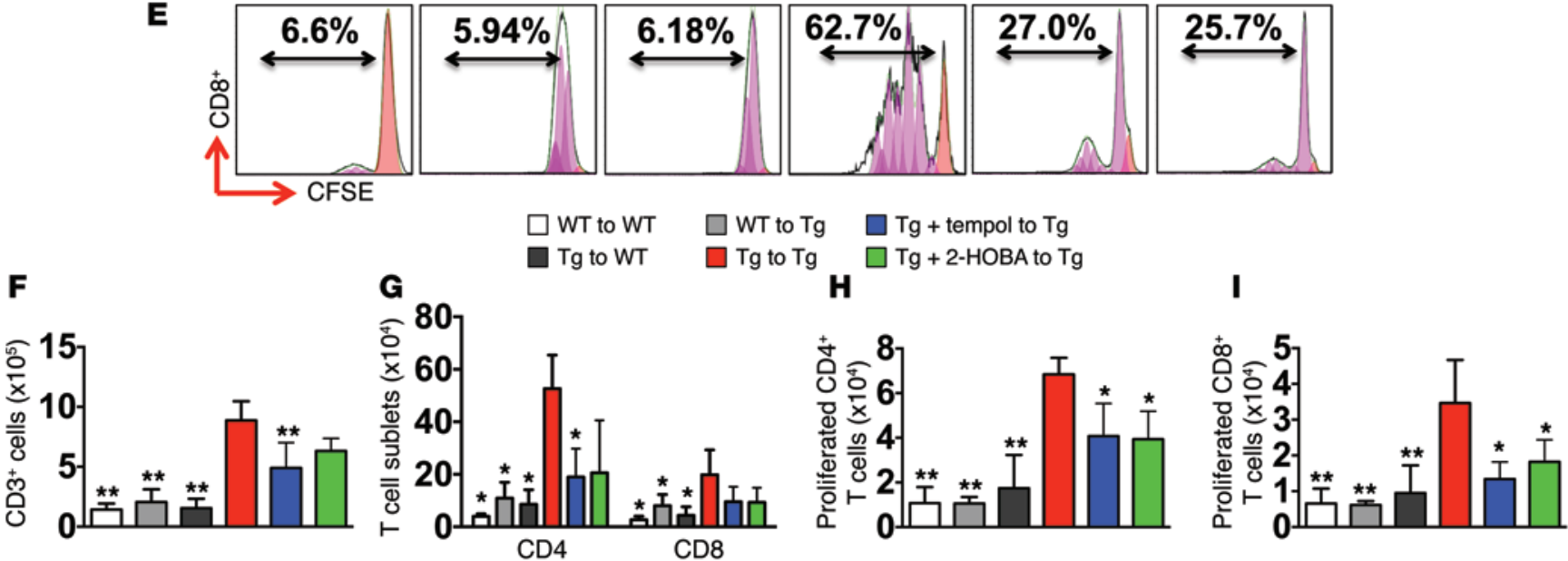

Figure 12. Tg $^{\text {sm/p22phox }}$ aortic homogenates prime DCs to promote $T$ cell proliferation and activation. (A) Experimental design. Aortic homogenates from WT or tg $\mathrm{g}^{\text {sm/p22phox }}$ mice were used to prime naive DCs, which were then cocultured with T cells from these mice in various combinations. (B, C, F, and $\mathbf{G}$ ) Flow cytometry and bar graphs identifying live $C D 3^{+} T$ cells and $C D 4^{+} / C D 8^{+} T$ cell subsets from cocultured DCs and T cells. (D, E, H, and I) Representative flow cytometry images and bar graphs showing percentages and numbers of proliferating $C D 4^{+}(\mathbf{D}$ and $\mathbf{H})$ and $C D 8^{+}(\mathbf{E}$ and $\mathbf{I}) \mathrm{T}$ cells, as determined using CSFE dilution ( $n=6,1$-way ANOVA). Homo, homogenates. Black lines indicate original data, orange peaks indicate initial population, and purple peaks indicate generations of cells undergoing division as simulated by Flowjo 7.6.4 software. ${ }^{*} P<0.05$ compared with $\operatorname{Tg}^{\text {sm/p22phox }}$ homogenate $+\operatorname{Tg}^{\text {sm/p22phox }} T$ cells; ${ }^{* *} P<0.01 \mathrm{Tg}^{\text {sm/p22phox }}$ homogenate $+\mathrm{Tg}^{\text {sm/p22phox }} \mathrm{T}$ cells.

mals prior to development of hypertension. At 9 months, these mice develop modest elevations of blood pressure, while WT mice remain normotensive at this age. We also observed identical chronological changes in aortic stiffening and hypertension in mice with targeted vascular smooth muscle deletion of Sod3. Hemodynamic changes caused by aortic stiffening, including increased PWV and higher forward pressure wave amplitude, contribute separately to the risk of adverse cardiovascular outcomes $(3,4)$. Of note, PWV is elevated in $\operatorname{tg}^{\mathrm{sm} / \mathrm{p} 22 \mathrm{phox}}$ mice at 6 months of age, prior to the development of renal inflammation, fibrosis, and dysfunction, supporting the notion that aortic stiffening directly causes renal damage and, ultimately, hypertension. Taken 
Table 1. Vascular oxidative stress-induced DC activation and cytokine production

\begin{tabular}{|c|c|c|c|c|c|c|}
\hline Cytokine (pg/ml) & $\begin{array}{l}\mathrm{WT}^{\mathrm{A}} \\
\mathrm{WT}^{\mathrm{B}}\end{array}$ & $\begin{array}{c}\mathrm{WT}^{\mathrm{A}} \\
\mathrm{Tg}^{\mathrm{sm} / \mathrm{p} 22 \mathrm{phox} B}\end{array}$ & $\begin{array}{c}\mathrm{Tg}^{\text {sm/p22phox A }} \\
\mathrm{WT}^{\mathrm{B}}\end{array}$ & $\begin{array}{l}\operatorname{Tg}^{\text {sm/p22phox A }} \\
\operatorname{Tg}^{\text {sm/p22phox B }}\end{array}$ & $\begin{array}{c}\operatorname{Tg}^{\text {sm/p22phox }}+\text { Tempol }^{A} \\
\operatorname{Tg}^{\text {sm/p22phox B }}\end{array}$ & $\begin{array}{c}\mathrm{Tg}^{\text {sm/p22phox }}+2-\mathrm{HOBA}^{\mathrm{A}} \\
\mathrm{Tg}^{\text {sm/p22phox B }}\end{array}$ \\
\hline GM-CSF & $12.99 \pm 1.42^{D}$ & $8.24 \pm 2.18^{D}$ & $23.47 \pm 11.17^{0}$ & $1450.50 \pm 620.01$ & $45.04 \pm 28.71^{D}$ & $73.80 \pm 58.52^{D}$ \\
\hline $\mathrm{IL}-1 \alpha$ & $10.27 \pm 4.23^{\complement}$ & $5.17 \pm 1.71^{\complement}$ & $23.15 \pm 10.99$ & $44.43 \pm 9.48$ & $19.46 \pm 9.40$ & $14.40 \pm 3.35$ \\
\hline IL-1 $\beta$ & $7.33 \pm 2.58^{D}$ & $5.51 \pm 1.97^{D}$ & $12.51 \pm 4.59^{\circ}$ & $52.03 \pm 8.80$ & $14.96 \pm 3.14^{D}$ & $17.41 \pm 11.26^{D}$ \\
\hline IL-2 & $5.60 \pm 1.48$ & $16.92 \pm 5.42$ & $4.70 \pm 1.25$ & $8.26 \pm 2.41$ & $14.01 \pm 6.02$ & $15.16 \pm 5.17$ \\
\hline IL-6 & $20.63 \pm 9.43^{D}$ & $28.64 \pm 12.70^{\circ}$ & $39.10 \pm 17.35^{\circ}$ & $1461.00 \pm 439.78$ & $122.42 \pm 76.91^{0}$ & $215.62 \pm 126.10^{0}$ \\
\hline IL-12(p40) & $3.20 \pm 0.00$ & $3.20 \pm 0.00$ & $15.89 \pm 12.69$ & $4.03 \pm 0.51$ & $6.66 \pm 2.77$ & $3.20 \pm 0.00$ \\
\hline IL-12(p70) & $3.20 \pm 0.00$ & $3.20 \pm 0.00$ & $5.25 \pm 2.06$ & $3.20 \pm 0.00$ & $3.55 \pm 0.44$ & $3.20 \pm 0.00$ \\
\hline IL-21 & Undetectable & Undetectable & Undetectable & Undetectable & Undetectable & Undetectable \\
\hline IL-23 & Undetectable & Undetectable & Undetectable & Undetectable & Undetectable & Undetectable \\
\hline TGF- $\beta 1$ & $598.25 \pm 89.60^{D}$ & $779.67 \pm 79.89$ & $733.25 \pm 50.09 c$ & $1078.00 \pm 121.93$ & $807.20 \pm 56.93$ & $860.60 \pm 75.65$ \\
\hline TGF- $\beta 2$ & Undetectable & Undetectable & Undetectable & Undetectable & Undetectable & Undetectable \\
\hline TGF- $\beta 3$ & $194.25 \pm 5.92$ & $184.33 \pm 5.589^{\circ}$ & $189.00 \pm 1.68^{\complement}$ & $218.00 \pm 10.19$ & $188.20 \pm 4.859^{\circ}$ & $190.00 \pm 3.54^{\complement}$ \\
\hline IL-17A & $20.06 \pm 2.27^{0}$ & $288.02 \pm 223.47^{\complement}$ & $30.24 \pm 11.86^{D}$ & $4433.50 \pm 1871.88$ & $219.88 \pm 153.60^{\circ}$ & $298.38 \pm 197.49^{\circ}$ \\
\hline IL-17F & $4.23 \pm 0.00^{\circ}$ & $49.49 \pm 39.19^{D}$ & $15.80 \pm 11.57^{0}$ & $920.00 \pm 111.09$ & $155.62 \pm 124.28^{\circ}$ & $142.70 \pm 88.87^{\circ}$ \\
\hline IFN- $\gamma$ & $3.20 \pm 0.00^{D}$ & $38.47 \pm 30.54^{D}$ & $4.87 \pm 1.17^{D}$ & $3848.25 \pm 2662.32$ & $50.53 \pm 52.53^{D}$ & $110.15 \pm 72.34^{0}$ \\
\hline TNF- $\alpha$ & $7.66 \pm 2.54^{D}$ & $10.69 \pm 5.07^{D}$ & $13.26 \pm 5.14^{\mathrm{D}}$ & $83.45 \pm 8.10$ & $21.73 \pm 5.57^{D}$ & $23.58 \pm 8.08^{D}$ \\
\hline
\end{tabular}

together, data from these 2 models suggest that mice with chronic vascular oxidative stress recapitulate age-related aortic stiffening and hypertension in humans and suggest that chronic vascular oxidative stress might contribute to the human disease.

Studies by our laboratory and others have implicated $\mathrm{T}$ cellderived cytokines in the development of tissue fibrosis and target organ damage in hypertension (13-16, 30). In the present study, we found that vascular oxidative stress induces production of IL-17A by splenic T cells. Moreover, DCs primed with aortic homogenates from $\mathrm{tg}^{\mathrm{sm} / \mathrm{p} 22 \text { phox }}$ mice markedly activate $\mathrm{T}$ cells from this same genotype but not $\mathrm{T}$ cells from WT mice. This activation profile included not only proliferation, but also robust production of IL-17A, IL-17F, TNF- $\alpha$, and IFN- $\gamma$. These observations support a pathway in which vascular oxidative stress leads to formation of isoketal-protein adducts that are taken up by DCs that, in turn, can activate T cells. Of note, we have previously shown that IL-17A induces fibroblast production of collagen via activation of p38 MAP kinase (15). Similarly, Valente et al. have shown that IL-17A stimulates mouse cardiac fibroblast migration and proliferation via a p38 MAP kinase pathway (31). IFN- $\gamma$ also mediates cardiac inflammation and fibrosis in angiotensin II-infused WT mice, and IFN- $\gamma$ receptor-deficient mice are protected from these changes (16). In addition, TNF- $\alpha$ has been implicated in angiotensin II-induced hypertension, and TNF- $\alpha$ antagonist treatment improves parameters of aortic compliance in humans with autoimmune disease $(11,13)$. Thus, the milieu of Th1/ Th17 cytokines stimulated by isoketal-adducted proteins likely promotes age-related aortic stiffening and hypertension.

Related to the above considerations, a striking finding in the current study is the marked production of cytokines - including IL-1 $\beta$, IL-6, TGF- $\beta 1$, and GM-CSF - by DCs primed with $\operatorname{tg}^{\text {sm/p22phox }}$ aortic homogenates when exposed to $\mathrm{T}$ cells from $\mathrm{tg}^{\mathrm{sm} / \mathrm{p} 22 \mathrm{phox}}$ mice.
This suggests that not only do DCs stimulate $\mathrm{T}$ cell proliferation and cytokine production, but also that $\mathrm{T}$ cells with $\mathrm{T}$ cell receptors that respond to isoketal adducts reciprocally activate DCs. One such signal might involve costimulatory engagement of DC B7 ligands by T cell CD28, which we have previously shown to be critical for hypertension and $\mathrm{T}$ cell activation in this disease (32). In this regard, Orabona et al. have shown that CD28 can stimulate DCs to produce IL-6, IFN- $\gamma$, and to a lesser extent IL-23 in a B7 and p38 MAP kinase-dependent fashion (33).

Macrophages and monocytes can also function as APCs and have the capability to trigger adaptive immune responses in addition to professional DCs (25). In the present study, we found an increase of total $\mathrm{F} 4 / 80^{+}$cells in the aorta of $\mathrm{tg}^{\mathrm{sm} / \mathrm{p} 22 \text { phox }}$ mice with aging. In addition, we found that splenic macrophages and monocytes of $\mathrm{tg}^{\mathrm{sm} / \mathrm{p} 22 \mathrm{phox}}$ mice accumulate isoketal adducts. We have previously shown that monocyte/macrophage-like cells do not increase expression of the B7 ligands, CD80 and CD86, in concert with their acquisition of isoketal adducts as robustly as DCs, suggesting that they might not be as effective in T cell stimulation (18).

There is increasing awareness that posttranslational protein modification, such as citrullination and carbamylation, can lead to immune responses $(34,35)$. Our current and prior studies indicate that the covalent modification of self-proteins by isoketals might represent a similar phenomenon (36) and provide a mechanism by which chronic oxidative stress can lead to systemic immune activation. Despite the plethora of studies implicating ROS in diseases such as atherosclerosis, hypertension, and diabetes, several large clinical trials using either vitamin $\mathrm{E}$ or combinations of antioxidants have failed to show any decrease in cardiovascular morbidity or mortality $(37,38)$, and high doses of vitamin $\mathrm{E}$ have paradoxically been associated with increased cardiovascular event rates 
A

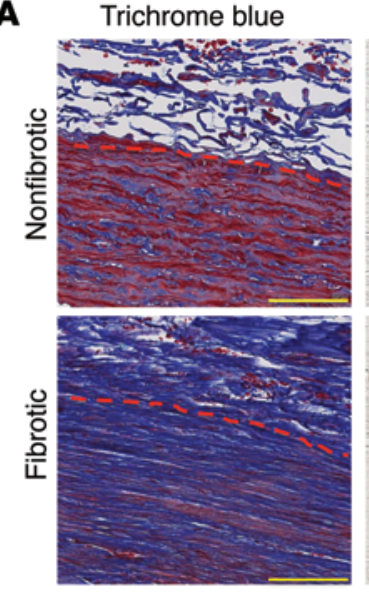

B

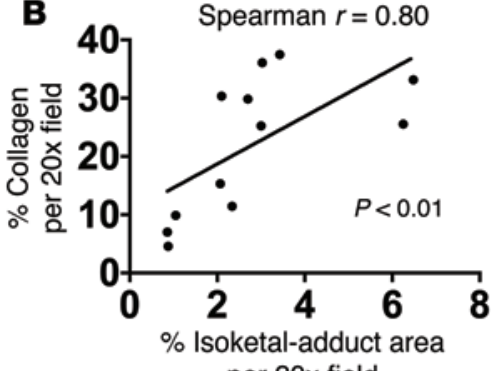
per 20x field
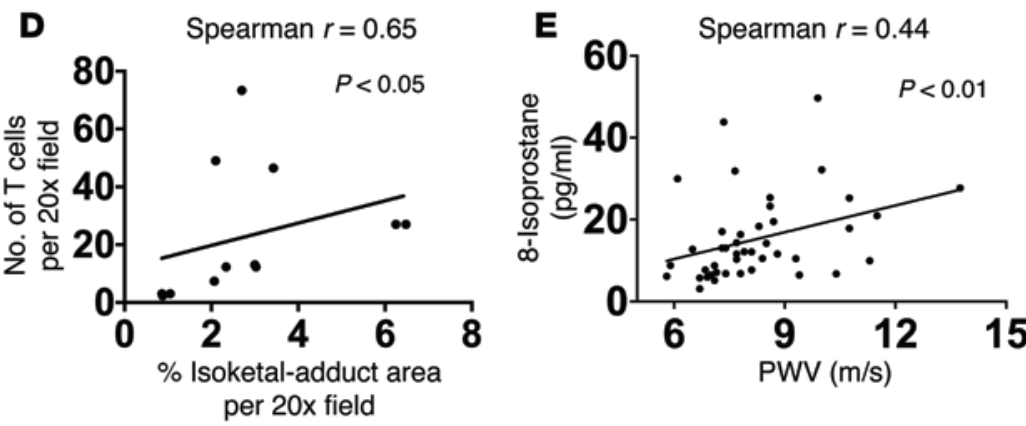

Figure 13. Role of isoketal and oxidation in aortic collagen deposition and stiffening in humans. (A-D) Data from human aortas. (E) Comparison of PWV and isoprostane content in patients. Consecutive $6 \mu \mathrm{m}$ sections were stained with anti-CD3, D-11 ScFv, and Masson's trichrome blue (A). Images are $\times 20$ magnification. Scale bars: $100 \mu \mathrm{m}$. Image J was used to quantify the area of D-11 staining for isoketal adducts and the area of blue in the Masson's trichrome stains. Human T cells were quantified by counting positively stained cells per $\times 20$ field (B and $\mathbf{C}$ ). Spearman's correlations comparing PWV and 8-isoprostanes in normotensive and treated hypertensive humans (E). M, media; A, adventitia.

age were implanted with telemetry units. Ten days later, blood pressure was recorded for 10 minutes every hour for 3 days. In additional $\operatorname{tg}^{\text {sm/p22phox }}$ mice, tempol $(n=6)$ or 2-HOBA $(n=6)$ was administered in the drinking water from 4-9 months of age. In some experiments, 3-month-

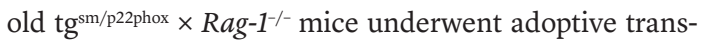
fer of $\mathrm{T}$ cells as described previously $(13,15,32)$. Ninemonth-old tg $^{\text {sm/p22phox }} \times$ Rag-1 $^{-/-}$mice, with or without $\mathrm{T}$ cell reconstitution, were used for blood pressure and vascular stiffness measurements. Sod $3^{f / f l}$ Smmhc-Cre mice and $\operatorname{Sod} 3^{f / f l} \times \mathrm{Cre}^{-}$mice were treated with tamoxifen ( $3 \mathrm{mg} / 20 \mathrm{~kg}$, dissolved in corn oil) via 5 consecutive i.p. injections at 10 weeks of age and were studied at 9 months of age (21).

Power spectral analysis of heart rate variability. Blood pressure was recorded by telemetry for 5 minutes every hour at a sampling rate of $500 \mathrm{~Hz}$, and data were extracted from waveform pressure. Heart rate variability was analyzed from multiple artifact-free blood pressure records of each mouse by LabChart Pro software (ADInstruments). Power spectra were calculated as previously described (21).

Ex vivo measurement of aortic stiffness. For studies of vascular stiffness, the descending thoracic aorta was mounted on cannulas at the in situ length in calciumfree buffer (44). Intraluminal pressure was increased in a step-wise fashion while video microscopy was used to follow wall thickness and vessel diameter. Diameters were recorded at increments of $25 \mathrm{mmHg}$ from 0-200 $\mathrm{mmHg}$. Stress-strain relationships were calculated as described by Baumbach et al. (44). Hydroxyproline was measured in isolated thoracic aortas as previously described (45-47).

In vivo measurement of $P W V$. PWV was measured using the transit time method with Doppler ultrasound (Vevo 2100, VisualSonics) as previously described (20). Briefly, mice were anesthetized with $2 \%$ isoflurane/air and maintained under light anesthesia. Mice were kept at supine positions on a heated platform $\left(38^{\circ} \mathrm{C}\right)$ with ECG electrodes taped to their paws for continuous recordings. Thoracic and abdominal hair was removed. Pressure waveforms were imaged $1 \mathrm{~mm}$ below the exit to the left subclavian artery and $1 \mathrm{~mm}$ above the exit to left renal artery on the descending aorta. Arrival times were calculated based on the distances between the foot of the pres-

(39), perhaps because ROS can have important signaling functions that modulate vascular tone, cell growth, and survival (40-42) and are critical for innate immunity. We have previously shown that these higher concentrations of vitamin $\mathrm{E}$ are required to suppress plasma F2 isoprostanes, which form from the same precursors as isoketals (43). It is therefore possible that agents such as 2-HOBA, which directly scavenge isoketals with a high rate constant and do not interfere with other ROS, will prove beneficial in treatment of disorders such as hypertension and aortic stiffening.

\section{Methods}

Animals. Male WT and $\operatorname{tg}^{\mathrm{sm} / \mathrm{p} 22 \text { phox }}$ mice were studied at 3, 6, and 9 months of age. For measurement of blood pressure, 6 mice at each sure waveform and the peak of $\mathrm{R}$ wave for both the proximal and distal locations (Supplemental Figure 1B). The transit time was calculated as the difference in these arrival times and was averaged over 5 cardiac cycles. The in situ distances between these 2 positions were measured postmortem with a ruler. PWV $(\mathrm{m} / \mathrm{s})$ was calculated by dividing the distance by the transit time.

Flow cytometry. Single cell suspensions were prepared from aortas as previously described $(15,32)$. Briefly, the entire aorta with surrounding perivascular fat was minced with fine scissors and digested with 1 $\mathrm{mg} / \mathrm{ml}$ collagenase A, $1 \mathrm{mg} / \mathrm{ml}$ collagenase B, and $100 \mu \mathrm{g} / \mathrm{ml}$ DNAase I in phenol-free RPMI 1640 medium with $5 \%$ FBS for 30 minutes at $37^{\circ} \mathrm{C}$, with intermittent agitation. Fc receptors were blocked with $\mathrm{CD} 16 / \mathrm{CD} 32$ for 20 minutes at $4^{\circ} \mathrm{C}$ (clone 2.4G2, BD Biosciences) prior 
Table 2. Characteristics of study groups

$\begin{array}{lcc} & \text { NT }(\boldsymbol{n}=15) & \text { HTN }(\boldsymbol{n}=\mathbf{2 8}) \\ \text { Age (year) } & 50.9 \pm 5.7 & 58.1 \pm 11.2^{\mathrm{A}} \\ \text { Sex (female/male) } & 13 / 15 & 8 / 7 \\ \text { BMI (kg/m²) } & 25.2 \pm 2.6 & 29.9 \pm 5.4^{\mathrm{A}} \\ \text { Office SBP (mmHg) } & 120 \pm 14 & 129 \pm 9^{A} \\ \text { Office DBP (mmHg) } & 77 \pm 9 & 80 \pm 8 \\ \text { PWV (m/s) } & 7.2 \pm 0.9 & 8.8 \pm 1.7^{\mathrm{A}} \\ \text { Fasting glucose (mg/dl) } & 83.7 \pm 9.1 & 99.5 \pm 18.5^{\mathrm{A}} \\ \text { HbA1C (\%) } & 5.2 \pm 0.2 & 6 \pm 0.6^{A} \\ \text { Total cholesterol (mg/dl) } & 212 \pm 41 & 206 \pm 38 \\ \text { LDL (mg/dl) } & 129 \pm 38 & 128 \pm 31 \\ \text { F2-isoprostanes (ng/ml) } & 10.7 \pm 1.6 & 17.7 \pm 2.2^{A}\end{array}$

Drugs

$\begin{array}{lll}\text { Thiazide diuretics (\%) } & 0 & 70 \\ \text { ACEi (\%) } & 0 & 30 \\ \text { ARB (\%) } & 0 & 41 \\ \text { CCB (\%) } & 0 & 30 \\ \beta \text {-blockers (\%) } & 0 & 41 \\ \text { Other anti-HT drugs (\%) } & 0 & 7\end{array}$

NT, normotensive subjects; $H T$, patients with well-controlled hypertension; SBP, systolic blood pressure; DBP, diastolic blood pressure; HbA1C, glycated hemoglobin; $\mathrm{ACEi}$, angiotensin I-converting enzyme inhibitor; ARB, angiotensin receptor blocker; CCB, calcium channel blocker. ${ }^{A} P<0.05$.

to the staining of surface markers. The antibodies used were: Amcyan anti-CD45 (clone 2D1, BD Biosciences), PE anti-F4/80 (clone BM8, eBioscience), Pacific Blue anti-CD19 (clone 6D5, BioLegend), APCCy7 anti-CD3e (clone 145-2C11, BD Biosciences), APC anti-CD4 (clone GK1.5, eBioscience), and PE-Cy7 anti-CD8a (clone 53-6.7, BD Biosciences). Cells $\left(1 \times 10^{6}\right)$ were incubated with $1.5 \mu \mathrm{l}$ of each antibody in $100 \mu \mathrm{l}$ of FACS buffer for 35 minutes. The cells were then washed twice with FACS buffer and immediately analyzed on a FACSCanto flow cytometer with DIVA software (BD Biosciences). Dead cells were eliminated from analysis using 7-AAD (catalog 559925, BD Biosciences). For each experiment, we performed flow minus one (FMO) controls for each fluorophore to establish gates. Data analysis was performed using FlowJo software (Tree Star Inc.).

Intracellular staining of splenocytes. Splenocytes $\left(1 \times 10^{6}\right)$ were resuspended in RPMI medium supplemented with 5\% FBS and stimulated with ionomycin and phorbol myristate acetate and brefeldin A at $37^{\circ} \mathrm{C}$ for 5 hours. Dead cells were excluded from analysis with a fixable Violet dead cell stain. The following surface antibodies were employed for staining T cells: BV510 anti-CD45 (clone 2D1, BD Biosciences), PerCP-Cy5.5 anti-CD3e (clone 145-2C11, BD Biosciences), PE-Cy7 anti-CD8a (clone 53-6.7, BD Biosciences), and APC-H7 anti-CD4 (clone GK1.5, BD Biosciences). Intracellular staining was then performed with the Cytofix/Cytoperm Plus fixation/ permeabilization solution kit (BD Biosciences) using PE anti-IL-17A (clone eBio17B7, eBioscience), and FITC anti-IFN- $\gamma$ antibodies (clone XMG1.2, eBioscience). In some experiments, macrophages, DCs, and monocytes were gated using APC anti-CD11b (clone M1/70, BD Biosciences), PE anti-MerTK (clone HMER5DS, eBioscience), APC-Cy7 anti-CD11c (clone HL3, BD Biosciences), PerCP-Cy5.5 MHC-II/I-A b (clone M5/114.15.2, BD Biosciences), PE-Cy7 anti-CD64 (clone X54-
5/7.1, BioLegend), AmCyan anti-F4/80 (clone BM8, BioLegend), and Alexa Fluor 700 anti-Ly-6C (clone AL-21, BD Biosciences) as previously described (25). A single chain antibody, D11 ScFv, was conjugated to Alexa Fluor 488 (catalog A10468, Invitrogen) for the detection of isoketals in these cells.

Measurement of isoketal adducts. Isoketals in mouse aortas were also measured as the isoketal-lysyl-lactam adducts using MS analysis as previously described $(18,48)$. To detect DC isoketal adducted peptides by dot blot analysis, DCs from the spleen of 9-month-old WT or $\operatorname{tg}^{\mathrm{sm} / \mathrm{p} 22 \text { phox }}$ mice were sorted using a Miltenyi Biotec DC isolation kit to positively select $\mathrm{IAb}^{+} / \mathrm{CD} 11 \mathrm{~b}^{+} / \mathrm{CD} 11 \mathrm{c}^{+}$cells. The cells were placed in citrate-phosphate buffer at $\mathrm{pH} 3.3$ containing a protease inhibitor cocktail and iodoacetamide (1:100) to elute MHCbound peptides. The peptides were then passed through ultrafiltration devices (Amicon Ultra, Millipore) to isolate peptides $<5,000 \mathrm{Da}$ and to remove $\beta 2$-microglobulin proteins. Dot blot analysis was carried out on the resulting flow-through to detect isoketal-adducted peptides using D11 ScFv.

$T$ cell proliferation assay. Aorta homogenates were obtained from WT mice, $\operatorname{tg}^{\text {sm/p22phox }}$ mice, or $\operatorname{tg}^{\text {sm/p22phox }}$ mice chronically treated with tempol or 2-HOBA. Protein concentrations were determined in these samples using Bradford assay. CD11 $\mathrm{c}^{+}$DCs were isolated from total splenocytes of WT mice using a magnetic cell sorter and a commercially available kit (Miltenyi Biotec). This is an acceptable method to isolate essentially all DCs from mouse splenocytes. One million DCs were exposed to $100 \mathrm{mg}$ aortic protein for 2 hours in RPMI 1640 with $10 \%$ FBS, 5\% penicillin/streptomycin/fungizone, and $5 \%$ sodium pyruvate. These DCs were washed twice before being cocultured for 7 days with pan T cells prelabeled with CFSE (catalog C34554, Invitrogen). T cells were obtained from 9-monthold WT mice or $\operatorname{tg}^{\mathrm{sm} / \mathrm{p} 22 \text { phox }}$ mice that had either been untreated or chronically treated with tempol or 2-HOBA in the drinking water. Various combinations of aorta homogenate and $\mathrm{T}$ cells were employed as described in Figure 9, A and B. These cells were subjected to flow cytometry analysis, and cytokines in the culture medium were measured by luminex.

\section{Table 3. Multiple linear regressions for the association between log-transformed plasma 8-isoprostane levels and arterial stiffness}

$\begin{array}{lccc} & \boldsymbol{\beta} & \text { SEM } & \boldsymbol{P} \text { value } \\ \begin{array}{l}\text { Unadjusted model } \\ \text { Constant }\end{array} & 0.772 & 0.0483 & <0.001 \\ \text { Log 8-isoprostane } & 0.123 & 0.0427 & 0.006^{\mathrm{A}} \\ \text { Adjusted model } & & & \\ \text { Constant } & 0.497 & 0.122 & <0.001 \\ \text { Log 8-isoprostane } & 0.102 & 0.038 & 0.010^{\mathrm{A}} \\ \text { Age (year) } & 0.0040 & 0.0011 & <0.001^{\mathrm{A}} \\ \text { BMI (kg/m²) } & 0.00143 & 0.0024 & 0.557 \\ \text { SBP (mmHg) } & 0.00004 & 0.0009 & 0.968 \\ \text { Fasting glucose (mg/dl) } & 0.0003 & 0.0007 & 0.694\end{array}$

Unadjusted model $R=0.411, R^{2}=0.169$, adjusted $R^{2}=0.148$. Adjusted model, $R=0.681, R^{2}=0.463$. Adjusted $R^{2}=0.389$. $\beta$, beta coefficient; SEM, standard error; SBP, systolic blood pressure. $n=43$. ${ }^{A} P<0.05$. 

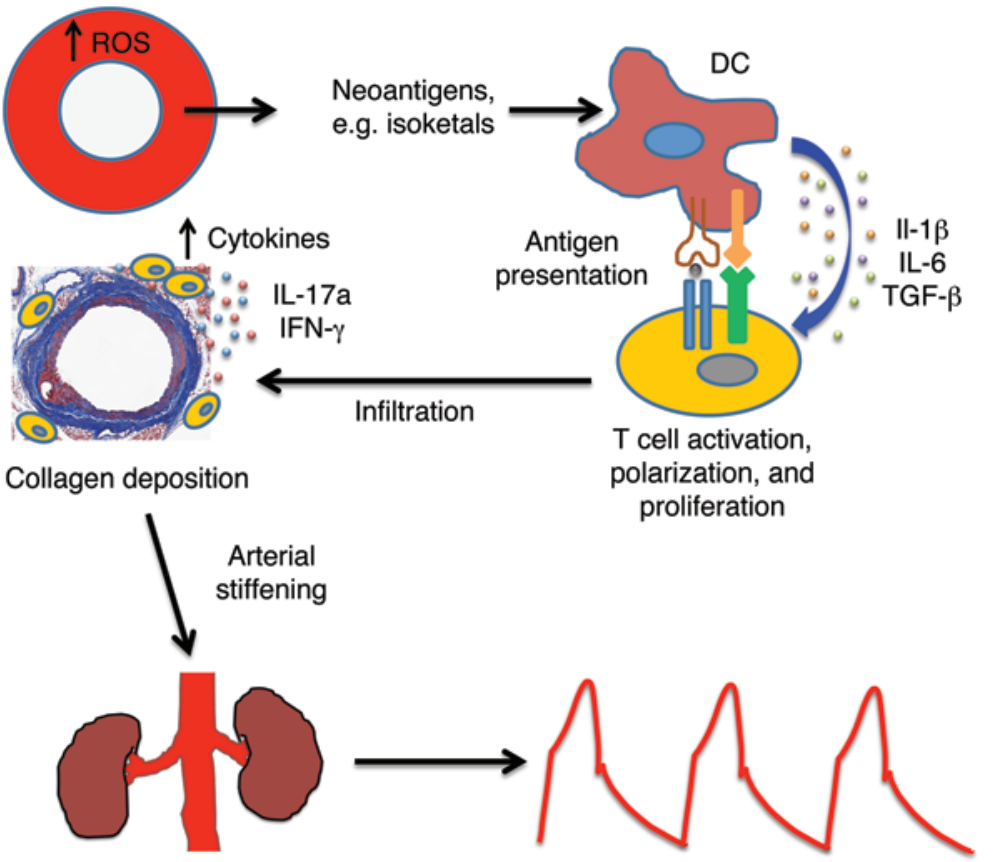

Renal inflammation, fibrosis, and dysfunction

Hypertension

Figure 14. Proposed pathway. Chronic vascular oxidative stress leads to formation of immunogenic isoketal-protein adducts, which accumulate in DCs and promote $\mathrm{T}$ cell activation. Activated $T$ cells accumulate in perivascular tissues and release cytokines that enhance collagen deposition and aortic stiffening. This enhances pulse wave velocity. Renal inflammation and fibrosis follows these events, leading to overt hypertension.

IHC of mouse tissues. Consecutive 6-micron sections were obtained from paraffin-embedded mouse thoracic aorta and kidney. These sections were stained with anti-CD3 (clone 145-2C11, BD Biosciences), D-11 ScFv, and Masson's trichrome blue as previously described $(18,49)$. Image $\mathrm{J}$ was used to quantify the area of D-11 staining for isoketal adducts and the area of blue in the Masson's trichrome stains per $20 \times$ field.

Human studies. PWV was measured using the SphygmoCor System (AtCor Medical). Venous blood samples were collected in tubes containing heparin. Plasma 8-isoprostane was detected by an enzyme immunoassay EIA kit (Cayman Chemical).

Human aortic tissue samples were obtained by one of the authors (J.A. Curci) during the course of open revascularization procedures for atherosclerotic occlusive disease of the aorta or at the time of renal transplantation at Washington University, St Louis, Missouri, USA. All specimens were full thickness infrarenal aortic tissue that was discarded at the time of the procedure by the clinical team and were anonymously transferred to the laboratory for study. Portions of these tissue samples were fixed in formalin, embedded in paraffin, and sliced into 6-micron sections. Consecutive sections were stained with anti-CD3 (clone HIT3a, BD Biosciences), D-11 ScFv, and Masson's trichrome blue as previously described $(18,49)$. Human T cells were quantified by counting the number of positively stained cells per $20 \times$ field. Five representative fields were quantified for each sample.

Statistics. Data in the manuscript are represented as mean \pm SEM. Comparisons of blood pressure over time and aortic mechanics were made using 1-way ANOVA for repeated measures, followed by a Bonfer- roni post hoc test when significance was indicated. To compare the effect of age on various mouse strains, 2-way ANOVA was employed. To compare the effects of antioxidant treatments and the effect of Rag-1 deficiency, 1-way ANOVA was performed. The values of cytokines were normalized with logarithmic transformation prior to 1-way ANOVA. Correlations between immune-staining parameters were made using Spearman's correlation analysis. Multivariate regression was used for analysis of human data. $P$ values are reported in the figures.

Study approval. All animal procedures were approved by Vanderbilt University's Institutional Animal Care and Use Committee, and the mice were housed and cared for in accordance with the Guide for the Care and Use of Laboratory Animals, US Department of Health and Human Services. The institutional review boards of Washington University and the University of Campinas approved the respective human studies. Subjects enrolled at Campinas signed a written informed consent form before enrolling in the study.

\section{Author contributions}

JW, MAS, AK, HAI, KRCM, LX, WC, SSD, and NRB performed experiments, analyzed data, and participated in manuscript preparation. SSD and LJR performed MS. JJG, CMW, KEB, LJR, HM, HC, MSM, and DGH participated in study design and manuscript preparation and obtained funding for the study. JAC provided human samples and assisted in manuscript preparation. HM supervised and obtained funding for human studies of PWV. RLM produced and provided the D11 antibody and assisted in experimental design.

\section{Acknowledgments}

We are grateful to the Transitional Pathology Shared Resource (TPSR) core and the Epithelial Biology Center at Vanderbilt University for assistance with imaging and quantification of immunohistochemical staining. We also thank the Vanderbilt University Medical Center Hormone Assay and Analytical Services Core (supported by NIH grants DK059637 and DK020593), who performed the cytokine measurements. We thank William Zackert for performing the MS and IHC for isoketal in the aorta samples. We also thank Zhizhang Wang in the Division of Cardiovascular Medicine at Vanderbilt University for his assistance in conducting in vivo measurement of PWV. This work was supported by NIH R01 grants HL105294, HL039006, and HL108701; VITA contract HHSN268201400010C; Program Project grants P01 HL58000 and GM015431; an American Heart Association predoctoral fellowship to J. Wu (13PRE14480008); and postdoctoral fellowship awards to A. Kirabo and M.A. Saleh. M.S. Madhur is the recipient of NIH KO8 award (1K08HL121671) and a Vanderbilt Physician Scientist Development Award. H.A. Itani is supported by NIH F32 training grant (1F32HL124972-01).

Address correspondence to: David G. Harrison, Betty and Jack Bailey Professor of Medicine and Pharmacology, Director of Clinical Pharmacology, Room 536 Robinson Research Building, Vanderbilt University, Nashville, Tennessee 37232-6602, USA. Phone: 615.875.3049; E-mail: david.g.harrison@vanderbilt.edu. 
1. Meaume S, Benetos A, Henry OF, Rudnichi A, Safar ME. Aortic pulse wave velocity predicts cardiovascular mortality in subjects > 70 years of age. Arterioscler Thromb Vasc Biol. 2001;21(12):2046-2050.

2. Laurent $\mathrm{S}$, et al. Aortic stiffness is an independent predictor of fatal stroke in essential hypertension. Stroke. 2003;34(5):1203-1206.

3. Kaess BM, et al. Aortic stiffness, blood pressure progression, and incident hypertension. JAMA. 2012;308(9):875-881.

4. Cooper LL, et al. Components of hemodynamic load and cardiovascular events: the Framingham Heart Study. Circulation. 2015;131(4):354-361.

5. Kals J, et al. Inflammation and oxidative stress are associated differently with endothelial function and arterial stiffness in healthy subjects and in patients with atherosclerosis. Scand J Clin Lab Invest. 2008;68(7):594-601.

6. Stephen EA, Venkatasubramaniam A, Good TA, Topoleski LD. The effect of oxidation on the mechanical response and microstructure of porcine aortas. J Biomed Mater Res A. 2014;102(9):3255-3262.

7. Soskel NT, Watanabe S, Sandberg LB. Mechanisms of lung injury in the copper-deficient hamster model of emphysema. Chest. 1984;85(6 suppl):70S-73S.

8. Galarraga B, Khan F, Kumar P, Pullar T, Belch JJ. Etanercept improves inflammation-associated arterial stiffness in rheumatoid arthritis. Rheumatology. 2009;48(11):1418-1423.

9. Selzer F, Sutton-Tyrrell K, Fitzgerald S, Tracy R, Kuller L, Manzi S. Vascular stiffness in women with systemic lupus erythematosus. Hypertension. 2001;37(4):1075-1082.

10. Gisondi P, et al. Chronic plaque psoriasis is associated with increased arterial stiffness. Dermatology. 2009;218(2):110-113.

11. Kume K, Amano K, Yamada S, Hatta K, Ohta H, Kuwaba N. Tocilizumab monotherapy reduces arterial stiffness as effectively as etanercept or adalimumab monotherapy in rheumatoid arthritis: an open-label randomized controlled trial. JRheumatol. 2011;38(10):2169-2171.

12. Angel K, Provan SA, Gulseth HL, Mowinckel P, Kvien TK, Atar D. Tumor necrosis factor- $\alpha$ antagonists improve aortic stiffness in patients with inflammatory arthropathies: a controlled study. Hypertension. 2010;55(2):333-338.

13. Guzik TJ, et al. Role of the $\mathrm{T}$ cell in the genesis of angiotensin II induced hypertension and vascular dysfunction. JExp Med.2007;204(10):2449-2460.

14. Madhur MS, et al. Interleukin 17 promotes angiotensin II-induced hypertension and vascular dysfunction. Hypertension. 2010;55(2):500-507.

15. Wu J, et al. Inflammation and mechanical stretch promote aortic stiffening in hypertension through activation of $\mathrm{p} 38$ mitogen-activated protein kinase. Circ Res. 2014;114(4):616-625.

16. Marko L, et al. Interferon- $\gamma$ signaling inhibition ameliorates angiotensin II-induced cardiac damage. Hypertension. 2012;60(6):1430-1436.

17. Miyashita $\mathrm{H}$, et al. Lysine pyrrolation is a naturally-occurring covalent modification involved in the production of DNA mimic proteins. Sci Rep. 2014;4:5343.

18. Kirabo A, et al. DC isoketal-modified proteins activate $\mathrm{T}$ cells and promote hypertension. J Clin Invest. 2014;124(10):4642-4656.

19. Laude K, et al. Hemodynamic and biochemical adaptations to vascular smooth muscle overexpression of p22phox in mice. Am J Physiol Heart Circ Physiol. 2005;288(1):H7-H12.

20. Weisbrod RM, et al. Arterial stiffening precedes systolic hypertension in diet-induced obesity. Hypertension. 2013;62(6):1105-1110.

21. Lob HE, Vinh A, Li L, Blinder Y, Offermanns S, Harrison DG. Role of vascular extracellular superoxide dismutase in hypertension. Hypertension. 2011;58(2):232-239.

22. Mattson DL, Lund H, Guo C, Rudemiller N, Geurts AM, Jacob H. Genetic mutation of recombination activating gene 1 in Dahl saltsensitive rats attenuates hypertension and renal damage. Am J Physiol Regul Integr Comp Physiol. 2013;304(6):R407-R414.

23. Trott DW, et al. Oligoclonal CD $8^{+} \mathrm{T}$ cells play a critical role in the development of hypertension. Hypertension. 2014;64(5):1108-1115.

24. Saleh MA, et al. Lymphocyte adaptor protein LNK deficiency exacerbates hypertension and end-organ inflammation. JClin Invest. 2015;125(3):1189-1202.

25. Jakubzick $C$, et al. Minimal differentiation of classical monocytes as they survey steady-state tissues and transport antigen to lymph nodes. Immunity. 2013;39(3):599-610.

26. Nguyen H, Chiasson VL, Chatterjee P, Kopriva SE, Young KJ, Mitchell BM. Interleukin-17 causes Rho-kinase-mediated endothelial dysfunction and hypertension. Cardiovasc Res. 2013;97(4):696-704.

27. Mitchell GF, et al. Cross-sectional correlates of increased aortic stiffness in the community: the Framingham Heart Study. Circulation. 2007;115(20):2628-2636.

28. Dietrich T, Schaefer-Graf U, Fleck E, Graf K. Aortic stiffness, impaired fasting glucose, and aging. Hypertension. 2010;55(1):18-20.

29. Mitchell GF, et al. Changes in arterial stiffness and wave reflection with advancing age in healthy men and women: the Framingham Heart Study. Hypertension. 2004;43(6):1239-1245.

30. Schrader LI, Kinzenbaw DA, Johnson AW, Faraci FM, Didion SP. IL-6 deficiency protects against angiotensin II induced endothelial dysfunction and hypertrophy. Arterioscler Thromb Vasc Biol. 2007;27(12):2576-2581.

31. Valente AJ, Yoshida T, Gardner JD, Somanna N, Delafontaine P, Chandrasekar B. Interleukin-17A stimulates cardiac fibroblast proliferation and migration via negative regulation of the dual-specificity phosphatase MKP-1/DUSP-1. Cell Signal. 2012;24(2):560-568.

32. Vinh $A$, et al. Inhibition and genetic ablation of the $\mathrm{B} 7 / \mathrm{CD} 28 \mathrm{~T}$-cell costimulation axis prevents experimental hypertension. Circulation. 2010;122(24):2529-2537.

33. Orabona C, et al. CD28 induces immunostim- ulatory signals in dendritic cells via CD80 and CD86. Nat Immunol. 2004;5(11):1134-1142.

34. Menard HA, Lapointe E, Rochdi MD, Zhou ZJ. Insights into rheumatoid arthritis derived from the Sa immune system. Arthritis Res. 2000;2(6):429-432.

35. Mydel P, et al. Carbamylation-dependent activation of T cells: a novel mechanism in the pathogenesis of autoimmune arthritis. JImmunol. 2010;184(12):6882-6890.

36. Kirabo A, et al. DC isoketal-modified proteins activate $\mathrm{T}$ cells and promote hypertension. J Clin Invest. 2014;124(10):4642-4656.

37. Czernichow S, et al. Effect of supplementation with antioxidants upon long-term risk of hypertension in the SU. J Hypertens. 2005;23(11):2013-2018.

38. Myung SK, et al. Efficacy of vitamin and antioxidant supplements in prevention of cardiovascular disease: systematic review and meta-analysis of randomised controlled trials. BMJ. 2013;346:f10.

39. Bjelakovic G, Nikolova D, Gluud LL, Simonett $\mathrm{RG}$, Gluud C. Mortality in randomized trials of antioxidant supplements for primary and secondary prevention: systematic review and meta-analysis. JAMA. 2007;297(8):842-857.

40. Matoba T, et al. Hydrogen peroxide is an endothelium-derived hyperpolarizing factor in human mesenteric arteries. Biochem Biophys Res Commun. 2002;290(3):909-913.

41. Arnold RS, et al. Hydrogen peroxide mediates the cell growth and transformation caused by the mitogenic oxidase Nox1. Proc Natl Acad Sci U S A. 2001;98(10):5550-5555.

42. Liu L, Wise DR, Diehl JA, Simon MC. Hypoxic reactive oxygen species regulate the integrated stress response and cell survival. J Biol Chem. 2008;283(45):31153-31162.

43. Roberts LJ. The relationship between dose of vitamin $\mathrm{E}$ and suppression of oxidative stress in humans. Free Radic Biol Med. 2007;43(10):1388-1393.

44. Baumbach GL, Siems JE, Heistad DD. Effects of local reduction in pressure on distensibility and composition of cerebral arterioles. Circ Res. 1991;68(2):338-351.

45. Mecham RP. Methods in elastic tissue biology: elastin isolation and purification. Methods. 2008;45(1):32-41.

46. Starcher B. A ninhydrin-based assay to quantitate the total protein content of tissue samples. Anal Biochem. 2001;292(1):125-129.

47. Hofman K, Hall B, Cleaver H, Marshall S. High-throughput quantification of hydroxyproline for determination of collagen. Anal Biochem. 2011;417(2):289-291.

48. Davies SS, Amarnath V, Brame CJ, Boutaud O, Roberts LJ. Measurement of chronic oxidative and inflammatory stress by quantification of isoketal/levuglandin $\gamma$-ketoaldehyde protein adducts using liquid chromatography tandem mass spectrometry. Nat Protoc. 2007;2(9):2079-2091.

49. Davies SS, et al. Localization of isoketal adducts in vivo using a single chain antibody. Free Radic Biol Med.2004;36(9):1163-1174. 